IZA DP No. 1082

A Search Model of Marriage with Differential Fecundity

Eugenio P. Giolito

March 2004 


\title{
A Search Model of Marriage with Differential Fecundity
}

\author{
Eugenio P. Giolito \\ University of Maryland \\ and IZA Bonn
}

\section{Discussion Paper No. 1082 \\ March 2004}

\author{
IZA \\ P.O. Box 7240 \\ 53072 Bonn \\ Germany \\ Phone: +49-228-3894-0 \\ Fax: +49-228-3894-180 \\ Email: iza@iza.org
}

\begin{abstract}
Any opinions expressed here are those of the author(s) and not those of the institute. Research disseminated by IZA may include views on policy, but the institute itself takes no institutional policy positions.

The Institute for the Study of Labor (IZA) in Bonn is a local and virtual international research center and a place of communication between science, politics and business. IZA is an independent nonprofit company supported by Deutsche Post World Net. The center is associated with the University of Bonn and offers a stimulating research environment through its research networks, research support, and visitors and doctoral programs. IZA engages in (i) original and internationally competitive research in all fields of labor economics, (ii) development of policy concepts, and (iii) dissemination of research results and concepts to the interested public.
\end{abstract}

IZA Discussion Papers often represent preliminary work and are circulated to encourage discussion. Citation of such a paper should account for its provisional character. A revised version may be available on the IZA website (www.iza.org) or directly from the author. 
IZA Discussion Paper No. 1082

March 2004

\section{ABSTRACT}

\section{A Search Model of Marriage with Differential Fecundity*}

It is commonly observed that over time and across societies, women tend to marry older men. The traditional explanation for this phenomenon is that wages increase with age and hence older men are more attractive in the marriage market. This explanation, however, involves an implicit assumption about female specialization in home production - an assumption that does not completely hold, especially in modern times.

This paper shows that a marriage market equilibrium where women marry earlier in life than men can be achieved without making any assumptions about the wage process or gender roles. The only driving force in this model is the asymmetry in fecundity horizons between men and women. When the model is calibrated with Census Data, the average age at first marriage and the pattern of the sex ratio of single men to single women over different age groups mimics the patterns observed in developed countries during the last decade (e.g. France, the U.S. and Sweden).

JEL Classification: J12, D83

Keywords: marriage markets, search, sex ratio

Eugenio P. Giolito

Department of Economics

University of Maryland

College Park

Tydings Hall, MD 20742

USA

Email: giolito@econ.umd.edu

\footnotetext{
* I am specially indebted to Lawrence Ausubel, Seth Sanders, William Evans, Jonah Gelbach, Rachel Kranton and John Rust for their support and encouragement. I also thank Julian Cristia, Eduardo Ganapolsky, Judy Hellerstein, Deborah Minehart, Roberto Muñoz, Michael Pries and Jeffrey Smith for their helpful comments. All the errors are of course mine.
} 


\section{Introduction}

It is commonly observed that, over time and across societies, women tend to marry older men. In the economics literature, the conventional explanation is that wages rise with age and hence men, who are the breadwinners in specialized families, are more attractive to women at older ages. Knowing this, young men will wait for the better marriage opportunities that come along with higher salaries at older ages. Historically this rationale played a role. For most of human history gender specialization in marriage was strong and many models rightfully reflected this strong historical specialization (e.g. Bergstrom and Bagnoli, 1993). ${ }^{1}$ However, with the tremendous rise in the labor force participation of women over the last four decades and the increasing fraction of families in which women earn more than men, the compelling nature of the conventional economic argument begins to break down.

If the conventional economic argument was the only explanation, the rise in women's economic independence should have relaxed the necessity of younger women marrying older men. In fact, between 1960 and 1990, female labor force participation rose from approximately $35 \%$ to approximately $60 \%$ (leveling off in the 1990's). During this time the wage gap (adjusting for skills) between women and men declined. Moreover, by the 1990s more than one-third of dual income families had women earning more than men. ${ }^{2}$ However, the age difference at marriage between men and women barely moved. According to the US Census, the difference in the median age between men and women at first marriage was 2.5 years in 1960 . Thirty years later, in spite of tremendous social changes the difference in the median age at first marriage between men and women was still 2.3 years.

The important changes in gender roles observed in the last decades occurred along side a delay of marriage for both sexes rather than a decrease in the age difference at first marriage between men and women. This is inconsistent with the purest version of the conventional economic model and is one reason to revisit our marriage models. A second reason is that, even when women specialized in home production, the economic model may not have been as important as has been suggested. For example, the common occurrence of a young woman marrying her high school sweetheart who is two years older, seems hard to explain using a

\footnotetext{
${ }^{1}$ Ted Bergstrom (1996) recognizes this fact when referring to his own theoretical model of marriage (Bergstrom and Bagnoli (1993)).

${ }^{2}$ See Winkler (1998)
} 
purely "gains-from-trade type" argument. With wages continuing to rise steeply with age among the young it is reasonable that even more gains to trade could occur if women married even older men. Finally, from a theoretical point of view, these models implicitly assume the myopia of women, imperfect capital markets or imperfect information about men's ability. It seems desirable to understand whether the age difference can be derived in a model without these auxiliary assumptions.

A handful of recent studies investigate a second potentially important factor leading younger women to marry older men - biology. It is a biological fact that women are fertile for less of their lives than are men. The consequence of this asymmetry in the fecundity horizons is that there will always be more fertile men than fertile women at any given point in time. Thinking of this imbalance as relative scarcity implies more bargaining power for the sex in short supply (in this case women) and competition among agents for the sex in abundant supply (in this case males). When this is true, one way that men may compete for women is through the resources they can bring to the marriage. When this insight is added to the upward sloping profile of wages with age, men may rationally wait to marry to compete better with younger men. (Siow (1998)). While this argument incorporates biology in a serious way, it is the age-wage profile that remains the underlying driving force of the market equilibrium. Biology, in this case, is simply the reason that justifies women as the scarce resource and justifies women choosing among men according to what they bring to the marriage and receiving the rent from their scarcity. One question that has not been addressed is whether the scarcity of fertile women arises in a world where individuals have rational expectations and are fully aware of the asymmetry between men and women that Siow describes. The point of departure for this paper is exactly this question: How does the equilibrium in the marriage market look when both men and women behave optimally and recognize that men have more time than women to search for the right mate and still have children?

Even assuming that asymmetric fecundity horizons play an important role in marriage market behavior, it remains unclear which aspects of the marriage market equilibrium are due to biology itself and which depend on a wage process where wages rise with age. The objective of this paper is limited to addressing the question: What can be explained exclusively by biology? Another reason for isolating the effects of biology independent of the wage processes is that while the latter varies considerably across societies, biology varies very little. Therefore, any prediction gleaned from a model that does not rely on upward sloping wage 
profiles is likely more applicable in a variety of social contexts. Furthermore, this framework does not need any additional assumptions about the perception of future earnings.

The model developed below is a two-sided general equilibrium search model where (as in most of the labor-related search literature) men and women are ex ante homogenous and utility is non-transferable. ${ }^{3}$ Only after a random meeting do the man and the woman receive signals about the match quality (match-specific heterogeneity). The purpose of the paper is to analyze how the agents' behavior and opportunity sets are affected by the asymmetry in the fecundity and (in the generalized version of this model) life horizons. Therefore, the age heterogeneity will be the crucial element here. ${ }^{4}$ In this model utility depends both on the quality of the match and on the joy derived from having children within marriage ${ }^{5}$. Unlike most of the previous marriage market literature, neither employment decisions nor capital accumulation is analyzed here. The total number of single men and women, and therefore the sex ratio, is determined endogenously in the model.

One of the major findings of this paper is that biology alone can provide an alternative explanation of the age difference between men and women at first marriage. Here, biology has two countervailing effects. First, as in Siow (1998), when women are young both older men and younger men compete for them making them scarce and hence raising the minimum acceptable match quality for marriage. By itself this would tend to make women marry at ages older than men. But offsetting this, forward-looking women, who know about their shorter fecundity horizon, reduce their optimal reservation value. The net result for reasonable parameter values is that, at most ages, women set an optimal reservation value that is relatively lower than the one a man of the same age sets. Therefore, women marry relatively younger than men because the biological clock induces them to accept a lower match quality even in the face of their relative scarcity at a given point in time. That result differs substantially from previous literature where relatively scarce fertile women are able to choose from a larger set of fertile men who "compete" for them. In addition, using the generalized version of the model, solved numerically, this work is able to quantify the age difference in marriage,

\footnotetext{
${ }^{3}$ Using non-transferable utility is helpful in order to provide a framework that is able to explain stylized facts about marriage independently of the potential gains of specialization, as it is common in the literature.

${ }^{4}$ There is an increasing theoretical literature about ex ante heterogeneous agents (for example Burdett and Coles (1997) and Smith (2002).

${ }^{5}$ The underlying assumption here is that people derive more utility from having biological children than from either having them out of wedlock or through adoption.
} 
the age composition of single males and females and the pattern of the sex ratio of singles along the life cycle. One of the features of these results is that a relatively large difference in the fecundity horizon (say, 20 years) leads to an age difference at first marriage that is much smaller (1.5 years). These results are then compared with Micro census Data for the US and other selected countries, from 1960 to 2000 .

The structure of the paper is as follows. Section 2 is a brief review of the literature on marriage market models. Section 3 outlines a simple 2-period model where women are only fertile in the first period and men in both periods. This model is solved analytically and is intended to set the basic conceptual framework in a simplified way. Section 4 extends the work by modeling the marriage choice as a finite-horizon dynamic programming problem and solving the model numerically - an extension that generates several stylized facts about marriage. Section 5 is devoted to comparing the implications of the model with US Census data and with data of selected countries. Specifically, it compares the pattern of the sex ratio of never-married people by age group in a generalized 60-period model (ages 16 to 75) with the census data. It finds that the pattern generated by the model fits data on the sex ratio in developed countries better than in developing countries, and fits better for more recent censuses than in previous decades. Section 6 concludes.

\section{Literature Review}

Since the publication of Gary Becker's first paper on marriage (Becker 1973) there has been growing interest in investigating decisions about marriage as if they occurred in a market. Becker argues that marriage has many aspects that are similar to trade of any other good in a market. Marriage is a voluntary contract between two people, or two families, who believe that they will be better off married than remaining single. Further, like buyers and sellers, many men and women compete to find mates. These aspects make marriage amenable to investigation as voluntary trade in a competitive market.

The compelling logic of this argument has spawned a large volume of research in both economics and sociology of both a theoretical and empirical nature. Much of the early literature followed up on Becker's insight and thought about one person, usually the woman, "purchasing" a mate in the marriage market. In this literature, women made decisions on marriage based on "meeting" men from the available pool and choosing whether to marry them or remain single. Men were passive agents and the bilateral nature of the marriage market was ignored. While 
these models were perhaps unrealistic in construct, they have had a major impact on the literature and on public policy. One well cited example is the work of Wilson and Neckerman (1986) who argue that the rise in out-of-wedlock childbearing among African-Americans is primarily a result of African-American women increasingly choosing not to marry from a shrinking pool of African-American men as they are deemed to be of insufficient quality to be "marriageable" (i.e. close to the women's age and education level, not in prison and employed).

Investigating this theory, Brien (1997) finds that while the pool of marriageable men does affect the age at first marriage, this mechanism explains very little of the difference in the timing of marriage (and fertility) between African-Americans and Whites. Other empirical examples where women are seen as choosing from a pool of available men include Fitzgerald (1991), Lichter et al. (1992), Wood (1995) and Schmidt (2002).

While empirical work has largely ignored the bilateral nature of marriage, theoretical work has had a rich tradition of investigating marriage as a bilateral process (either in a stable matching context (i.e. Gale and Shapley (1962), Roth and Sotomayor (1990)), or a dynamic search context (i.e. Mortensen (1988)). ${ }^{6}$

Most of the literature views utility of marriage arising solely from the quality of the match between the husband and the wife. ${ }^{7}$ However, clearly one of the main reasons that marriage occurs is for the production of children. While more recently, bearing children outside of marriage has become more common in developed countries, there are still reasons to believe that it is less costly, or of higher utility for parents to raise a child within marriage. For example, Willis and Weiss (1993) argue that children are a public good within marriage and as such both parents can derive utility from the child at the same time while sharing the cost of raising the child. This advantage is lost when a child's time needs to be divided between a custodial and non-custodial parent outside of marriage. In a real sense, the distinction of utility arising both from the marriage itself as well as from the children produced by it is unimportant when the marriage market is viewed as static (as the utility from the marriage can simply be redefined as the marriage's intrinsic value plus the expected utility from children produced from it at the time of marriage). But as we discuss below, when men and women are forward looking, and when fecundity falls with age, this distinction becomes important.

Bergstrom and Bagnoli (1993) present a model with incomplete information

\footnotetext{
${ }^{6}$ For detailed surveys about the search and matching literature, see Burdett and Coles (1999) and also Pissarides (2000)

${ }^{7}$ An exception is Siow (1998).
} 
where men who expect to be successful delay marriage until they are able to give a signal that allows them to attract more desirable women. The equilibrium of this model is that, while all women marry early in life, the most desirable women marry successful older men and the less desirable women marry young men who do not expect to prosper.

The interaction between marriage, labor market and human capital accumulation has also been addressed in the literature. Recent examples are Aiyagari et al. (2000), Seitz (2002) and Greenwood, Guner and Knowles (2002). Also, in a recent paper, Brien, Lillard and Stern (2002) analyze cohabitation before marriage as a learning process about match quality.

As noted above, Siow (1998) introduced the issue of the shorter fecundity period of women. ${ }^{8}$ In a model with capital accumulation and where utility comes exclusively from having children, old and young men (all fertile) compete for young women as by assumption infertile women do not participate in the market. Young men would always marry young women except that Siow allows wages to rise with age as well. Because of this some old men, those who successfully obtain a higher wage, are able to marry. This displaces some of the young men in the competition over scarce fertile women. Moreover, Siow argues that there is a relationship between the scarcity of fertile women and the fact that men are more likely to remarry after divorce. ${ }^{9}$ While it is hard to argue that, at any point of time, the stock of single fertile women is smaller than the stock of single fertile men, it is not clear whether this will be true in a dynamic framework. What this paper shows is that a market with more single men than women could be the equilibrium outcome where women, aware of their relatively limited fecundity horizon reduce their reservation value over the quality of a mate in order to ensure they marry when they are still in their fertile period.

\footnotetext{
${ }^{8}$ Tertilt (2002) uses a similar frameworrk to analyze the effects of polyginy.

${ }^{9}$ As Siow(1998) states in the introduction (pg. 335) "First, in monogamous societies with divorce and remarriage, fecund women are relatively scarce. For example, in North America, at least 30 percent of first marriages fail. Twenty percent of divorced women and 60 percent of divorced men will remarry. This differential in remarriage rates suggest that 12 percent of women who marry for the first time will marry divorced men. There are at least 12 percent fewer never-married to match with never-married men. Women will behave differently than men in response to this relative scarcity."
} 


\section{A Simple 2-period Model}

In this section we develop a simple overlapping generations model where people live two periods, women are fertile only in the first period and men are fertile in both periods. This simplification will allow us to obtain closed form solutions of the strategies and to prove existence and uniqueness. In the next section we will generalize this model allowing people to live a larger number of periods, and where the fecundity horizon for women is shorter than the one for men. The numerical solution for the generalized model is then compared with census data.

\subsection{Assumptions}

There is a continuum of single women of measure $F(t)$, and of men, $M(t)$. We will focus on the steady state, so $F(t)=F$ and $M(t)=M$.

In the spirit of Pissarides (1990), the number of contacts between single women and men is determined by a constant return to scale meeting function, as follows

$$
\eta=\mu M^{\theta} F^{1-\theta}
$$

where $0<\theta<1$ and $\mu$ a constant lower than $1 .^{10}$

Women will meet at most one man per period and vice versa. The probability of meeting someone of the opposite sex each period will depend the relative scarcity of each sex. For that reason, the probability that a single woman meets a single man is

$$
\eta^{f}=\mu\left(\frac{M}{F}\right)^{\theta}=\frac{\eta}{F}
$$

Similarly, the probability that a single man meets a single woman is

$$
\eta^{m}=\mu\left(\frac{M}{F}\right)^{\theta-1}=\frac{\eta}{M}
$$

All singles are ex-ante homogeneous except for their age and potential fecundity. The preferences over the opposite sex are idiosyncratic. As stated above, this paper focuses in how time affects marriage behavior; therefore this assumption, along with the one of random matching, are for simplicity and does not affect generality.

\footnotetext{
${ }^{10}$ This constant is merely a time scaling parameter introduced to ensure that the probability of meeting is lower than 1 and to allow a replication of the model in an arbitrary number of periods.
} 
Men and women differ in potential fecundity by age. While men are fertile at all ages, women are only fertile at age 1 .

Both men and women live two periods, ages 1 (young) and 2 (old). At any moment, there will be a number of women from both generations, $f_{1}$ of age 1 and $f_{2}$ of age 2 looking for a husband. Similarly these women will face a market of $m_{1}$ (young) and $m_{2}$ (old) bachelors.

Since men and women get married in pairs we need the number of young and old women that get married each period $\left(w_{1}\right.$ and $\left.w_{2}\right)$ to be equal to the total of men ( $h_{1}$ young plus $h_{2}$ old) who enter into marriage. That is:

$$
w_{1}+w_{2}=h_{1}+h_{2}
$$

Each period, an exogenous flow of single young people of age $1, f_{1}$ women and $m_{1}$ men (we assume $m_{1}=f_{1}$ ) enter the market. ${ }^{11}$ The men and women who have not married in the previous period will remain in the market. In the steady state, this flow of young people entering the market will be equal to the number of people who exit the market through marriage at any age plus the number that die single after period $2\left(f^{s}\right.$ old maids and $m^{s}$ old bachelors $) .{ }^{12}$. That is,

$$
\begin{aligned}
f_{1} & =w_{1}+w_{2}+f^{s} \\
m_{1} & =h_{1}+h_{2}+m^{s}
\end{aligned}
$$

Since the motivations of an eventual divorce and remarriage could be very different that the ones for first marriage, this topic is not investigated in this paper. ${ }^{13}$ We assume that people who divorce or whose spouse die do not re-enter the market. The meaning of this assumption is that, when single, people plan to marry only once in life. In other words, that at the moment people decide to marry the first time they believe that their marriage will last for the rest of their lives.

\footnotetext{
${ }^{11}$ As in Burdett and Coles (1997).

${ }^{12}$ Here we implicitly assume that the actual number of children that people have is the quantity needed to ensure the steady state with no population growth. Since the goal of this paper is to explain only the decision of marriage we assume the decision about the number of children as exogenous.

${ }^{13}$ For a model of marriage with "on the job" search and therefore endogenous separations, see Cornelius (2003)
} 
The stock of single female of each age will be

$$
\begin{aligned}
f_{2} & =f_{1}-w_{1} \\
f^{s} & =f_{2}-w_{2} \\
F & =f_{1}+f_{2}
\end{aligned}
$$

Similarly, the stock of single men of each age will be

$$
\begin{aligned}
m_{2} & =m_{1}-h_{1} \\
m^{s} & =m_{2}-h_{2} \\
M & =m_{1}+m_{2}
\end{aligned}
$$

The discount factor is equal to $\beta \in(0,1)$

The age composition of the marriage market is endogenously determined in the model. The fraction of young women and men,

$$
\begin{aligned}
& p=\frac{f_{1}}{F} \\
& q=\frac{m_{1}}{M}
\end{aligned}
$$

are simultaneously determined as a function of the reservation strategies of men and women.

\subsection{Payoffs}

Given that a man and a woman meet, their potential payoffs come from mutual compatibility and the utility of having children within marriage. We assume that both men and women will receive zero utility if they do not marry either in period one or two.

The specific utility that a woman receives from a man and vice versa are considered as independent random draws from the distribution $G_{m}(y)$ and $G_{f}(x)$, respectively. Assume that $G_{m}(y)$ has support [0,ymax $]$ and mean $\bar{y}$, and $G_{f}(x)$ has support $[0, x \max ]$ and mean $\bar{x} \cdot{ }^{14}$ Both distributions are strictly increasing on $x$ and $y$ respectively.

\footnotetext{
${ }^{14}$ In theory, $y$ or $x$ could take on negative values if the mean of both distributions were strictly positive. It sounds perfectly plausible that any man or woman could find that marrying certain canditates to be worse than staying single, and having children with these potential mates as a discount over having them out of wedlock. However, since the utility of being single is equal to 0 , the reservation values set by men and women will be always nonnegative and that assumption will become irrelevant.
} 
In addition, if a fertile man and a fertile woman meet, the utility is increased by a multiplicative parameter $k>1$ because of the possibility of having children together. For example, if a fertile man marries a fertile woman he will receive $k x$ per period and she will receive $k y$ per period. If either the man or the woman involved is infertile, both of them will only receive $x$ or $y$ respectively, that is, only the love of the other person.

The rationale for the parameter $k$ is that the value of a "having a family" will be a function of the attraction to their significant other. That is, people enjoy having children more with a person they care about. If we assume that people always receive utility from having children, we can separate it into two components, one coming from parenthood, and the other component coming from who the agent are having children with. Since it is possible to have children without a stable relationship, the specific joy of having children (and thus the utility out-of-wedlock parenthood) is normalized to 0 in this model. We assume further that the multiplicative parameter $k$ has a maximum such that the utility of marrying and have children with an average person can not be higher than the joy of finding a perfect match. That is,

$$
k \bar{x} \leq x \max \quad \text { and } \quad k \bar{y} \leq y \max
$$

Thus, the payoffs of marriage for men and women are the following:

\begin{tabular}{|c|c|c|}
\hline Women & Husband Age 1 & Husband Age 2 \\
\hline Marry at age 1 & $k y(1+\beta)$ & $k y$ \\
\hline Marry at age 2 & \multicolumn{2}{|c|}{$y$} \\
\hline
\end{tabular}

\begin{tabular}{|c|c|c|}
\hline Men & Wife Age 1 & Wife Age 2 \\
\hline Marry at age 1 & $k x(1+\beta)$ & $x$ \\
\hline Marry at age 2 & $k x$ & $x$ \\
\hline
\end{tabular}

\subsection{The Man's Optimization Problem ${ }^{15}$}

\subsubsection{Probability of a Marriage Offer for Men}

Let us first analyze the Male Problem. In each period a man will meet a woman with probability $\eta^{m}$ (by Equation (3)). The man will meet a single young woman

\footnotetext{
${ }^{15}$ Unless note otherwise I use the term man and woman in this Section to refer to single man and single woman.
} 
with probability $p$. This probability is equal to $\frac{f_{1}}{F}$ (the fraction of single women who are young), and this fraction (while endogenous to the market) is exogenous to each individual. However, the fact that he meets a young woman does not mean that he has a concrete opportunity to marry her. Even though all men are fertile, a given young woman will not be indifferent between a man of age 1 and of age 2 , because if she marries a senior bachelor she will enjoy his company for only one period. Hence she will set two different reservation values, $R^{f}$ for young men and $R_{\text {old }}^{f}$ for men of age 2 . In other words, a senior bachelor will have a probability of a marriage offer from a young woman (that is, to meet and also being accepted by a young woman) of

$$
\alpha_{2}^{\text {young }}=\eta^{m}\left[p\left(1-G_{m}\left(R_{\text {old }}^{f}\right)\right)\right]
$$

and a young man will receive an offer from a young woman with probability

$$
\alpha_{1}^{\text {young }}=\eta^{m}\left[p\left(1-G_{m}\left(R^{f}\right)\right)\right]
$$

Since old women will have reservation utility equal to 0 , they will accept any proposal. Then the probability that a given male receives and offer from an old woman will be

$$
\alpha^{\text {old }}=\eta^{m}(1-p)
$$

Given that a marriage offer is available, the man receives a signal drawn from the distribution $G_{f}(x)$ and decide to marry or not.

\subsubsection{Utility of Marriage for Men of Age 2 (Old)}

Old men who do not marry will die single, earning zero utility. The reservation value for an old man is therefore equal to 0 . He would be willing to marry any woman who makes him a marriage offer. If he meets a woman age 2 (who also has a reservation utility equal to 0 ), they will marry with certainty. If he meets a young woman (age 1) and he marries her, he will enjoy the extra utility from the prospect of having children ( $k$ times the type of the woman).

Therefore, the value of marrying at age 2 will be

$$
U_{2}^{m}=V_{2}^{m}=\left(\alpha_{2}^{\text {young }} k+\alpha^{\text {old }}\right) \bar{x}
$$




\subsubsection{Utility of Marriage for Men of Age 1 (Young)}

Since young men are able to wait until they are old in order to find the right mate, in period 1 men set a reservation value for accepting a woman taking into account next period prospects. As before, they can meet young or old women. Of course, if a young man marry a young woman, he will enjoy having children and live with his wife for two periods. If he marries an old woman he will be married for only one period and without children. Consequently, the reservation values of match quality a young man will set for marrying a young or an old woman will not be the same. Call these two reservation values $R^{m}$ and $R_{\text {old }}^{m}$, respectively. Moreover, in order to marry a young woman, he has to be accepted by her. This will happen with probability $\left(1-G_{m}\left(R^{f}\right)\right)$. The utility that a man derives from marrying at period 1 is then

$$
U_{1}^{m}=\alpha_{1}^{\text {young }} k(1+\beta) \int_{R^{m}}^{\bar{x}} x g_{f}(x) d x+\alpha^{\text {old }} \int_{R_{\text {old }}^{m}}^{\bar{x}} x g_{f}(x) d x
$$

\subsubsection{Optimization Problem for Young Men}

The problem that a young man faces is to choose to marry or not in order to maximize

$$
U_{1}^{m}+\left(1-\phi_{1}\right) \beta U_{2}^{m}
$$

The Bellman Equation of this Problem is

$$
V_{1}^{m}=\underset{D^{m}}{\operatorname{Max}}\left[U_{1}^{m}+\left(1-\phi_{1}\right) \beta V_{2}^{m}\right]
$$

where

$$
D^{m}= \begin{cases}1 & \text { if } x \geq R^{m} \text { or } x \geq R_{\text {old }}^{m} \\ 0 & \text { otherwise }\end{cases}
$$

here $D^{m}$ is the decision of marrying at at age 1 and

$$
\phi_{1}=\alpha_{1}^{\text {young }}\left(1-G_{f}\left(R^{m}\right)\right)+\alpha^{\text {old }}\left(1-G_{f}\left(R_{\text {old }}^{m}\right)\right)
$$

is the probability that a man marries at age 1 with a young or an old woman.

The reservation value set for an old woman is exactly equal to the discounted value that a man has if remains in the market at age 2 . Notice that, the to the 
linearity assumed in the utility function, the reservation value that men set for older women is $k(1+\beta)$ times the reservation value for young women. The reason for this is if he marries an old woman he will live with his wife only one period and without children. That is,

$$
\begin{aligned}
R^{m} & =\beta \frac{1}{k(1+\beta)} V_{2}^{m} \\
R_{\text {old }}^{m} & =\beta V_{2}^{m}=k(1+\beta) R^{m}
\end{aligned}
$$

\subsection{The Woman's Optimization Problem}

\subsubsection{Probability of a Marriage Offer for Women}

Now we can analyze the female problem. In each period, given the probability of meeting rate $\eta^{f}$ (by Equation (2)), a given woman will meet a young man with probability $q$ and an old man with probability $(1-q)$. She will marry him if the utility of marrying the man she meets, drawn from the distribution $G_{m}(y)$ is greater than the value of search for a better mate for one more period.

\subsubsection{Utility of Marriage for Women of Age 2 (Old)}

A woman is age 2 knows two things: first, she will die at the end of the period, and therefore her reservation value will $b e=0$; second, she is not fertile. This means that she will not receive the extra utility of having children, nor will she be able to provide that extra utility to any man she marries.

We can define the offer rates that a senior woman faces in the following way. A woman will meet a man each period with probability $\eta^{f}$. If she happen to meet an old man (with probability $(1-q)$ ) he will propose with probability 1 , and so she will have a concrete offer from an old bachelor with probability

$$
\lambda^{\text {old }}=\eta^{f}(1-q)
$$

If she meets a young man (with probability $q$ ) she will only marry him if her type $x$ is as least as large as his reservation utility for a senior bachelorette, $R_{\text {old }}^{m}$. For that reason, the probability that a young man proposes to a senior woman will be $\left(1-G_{f}\left(R_{\text {old }}^{m}\right)\right)$, what means that a senior bachelorette will receive a proposal from a young man with probability

$$
\lambda_{2}^{\text {young }}=\eta^{f} q\left(1-G_{f}\left(R_{\text {old }}^{m}\right)\right)
$$


Then the value of continue searching for an old woman is

$$
U_{2}^{f}=V_{2}^{f}=\left(\lambda_{2}^{\text {young }}+\lambda^{\text {old }}\right) \bar{y}
$$

\subsubsection{Utility of Marriage for Women of Age 1 (Young)}

A young woman sets a reservation value taking into account that she may have future opportunities to find a better spouse. However, if she doesn't marry young she will not be able to have children. Even though men of all ages are fertile, a young woman will not be indifferent between marrying a young man or an old man of the same match quality because a marriage with the old man lasts only for one period. Of course, while any old man will accept her, she will only be able to marry a young man if her match quality is higher than the reservation value set by him, $R^{m}$. A young man proposes to a young woman with probability $\left(1-G_{f}\left(R^{m}\right)\right)$. Thus, a young woman will receive a proposal from a young man with probability

$$
\lambda_{1}^{\text {young }}=\eta^{f} q\left(1-G_{f}\left(R^{m}\right)\right)
$$

The expected utility a woman receives from marrying when young is then

$$
U_{1}^{f}=\lambda_{1}^{\text {young }} k(1+\beta) \int_{R^{f}}^{y \max } y g_{m}(y) d y+\lambda^{\text {old }} k \int_{R_{\text {old }}^{f}}^{y \max } y g_{m}(y) d y
$$

\subsubsection{Optimization Problem for Young Women}

Hence, the problem facing a young woman is to choose to marry or not at Age 1 in order to maximize

$$
U_{1}^{f}+\left(1-\gamma_{1}\right) \beta V_{2}^{f}
$$

The Bellman Equation for this problem is then

$$
\begin{gathered}
V_{1}^{f}=\underset{D^{f}}{\operatorname{Max}}\left[U_{1}^{f}+\left(1-\gamma_{1}\right) \beta V_{2}^{f}\right] \\
D^{f}=\left\{\begin{array}{cc}
1 & \text { if } y \geq R^{f} \text { or } y \geq R_{\text {old }}^{f} \\
0 & \text { otherwise }
\end{array}\right.
\end{gathered}
$$

here $D^{f}$ is the decision of marrying at at age 1 and

$$
\gamma_{1}=\lambda_{1}^{\text {young }}\left(1-G_{m}\left(R^{f}\right)\right)+\lambda^{\text {old }}\left(1-G_{m}\left(R_{\text {old }}^{f}\right)\right)
$$


is the probability that a woman marries at age 1 .

The reservation value set for an old man is equal to the discounted value that a woman has if remains in the market at age 2 divided by $k$. Since men are fertile at all ages, if a woman marry at age 1 will have children with probability one, but if she waits until the second period she will not be able to bear children. Notice that, because all men are fertile, the reservation value that men set for older men is $(1+\beta)$ times the reservation value for young men (old men die first). That is,

$$
\begin{aligned}
R^{f} & =\beta \frac{1}{k(1+\beta)} V_{2}^{f} \\
R_{\text {old }}^{f} & =\beta \frac{1}{k} V_{2}^{f}=(1+\beta) R^{f}
\end{aligned}
$$

\subsection{Steady State Equilibrium}

\subsubsection{Reaction Functions}

Solving the problems stated in Equations (7) and (9), the reaction functions for men and women, respectively are

$$
\begin{aligned}
R^{m} & =\frac{\eta^{m} \beta\left[(1-p)+k p\left(1-G_{m}\left(R_{\text {old }}^{f}\right)\right)\right]}{k(1+\beta)} \bar{x} \\
R_{\text {old }}^{m} & =\eta^{m} \beta\left[(1-p)+k p\left(1-G_{m}\left(R_{\text {old }}^{f}\right)\right)\right] \bar{x} \\
R^{f} & =\frac{\beta \eta^{f}\left(1-q G_{f}\left(R_{\text {old }}^{m}\right)\right)}{k(1+\beta)} \bar{y} \\
R_{\text {old }}^{f} & =\frac{\beta \eta^{f}\left(1-q G_{f}\left(R_{\text {old }}^{m}\right)\right)}{k} \bar{y}
\end{aligned}
$$

Clearly, the higher a young man's reservation value, the greater the probability that he will still be in the market when old. Therefore, the higher the probability of being accepted by a women when he is older, the higher the minimum match quality he requires when young.

For women, the intuition is as follows. The reservation value of a woman depends positively on the average "match quality" of the available men, the degree

of patience and the meeting rate. Women will decrease their reservation value the higher the value of having children and the higher the reservation value that men set for older women, times the fraction of young men in the market. The 
explanation for this last factor is the following: the more choosy are young men about old women (and the greater the fraction of young men in the market), the larger the incentives of young women to worry about their future and marry young.

To facilitate the following proof, we define

$$
\begin{aligned}
T_{1}\left(R_{\text {old }}^{f}\right) & =\eta^{m} \beta\left[(1-p)+k p\left(1-G_{m}\left(R_{\text {old }}^{f}\right)\right)\right] \bar{x} \\
T_{2}\left(R_{\text {old }}^{m}\right) & =\frac{\beta \eta^{f}\left(1-q G_{f}\left(R_{\text {old }}^{m}\right)\right) \bar{y}}{k}
\end{aligned}
$$

In this notation, an equilibrium is characterized simply by the following equations:

$$
\begin{aligned}
& R_{\text {old }}^{m}=T_{1}\left(R_{\text {old }}^{f}\right) \\
& R_{\text {old }}^{f}=T_{2}\left(R_{\text {old }}^{m}\right)
\end{aligned}
$$

The following theorem establishes that there exists a unique solution system formed by Equations (11) and (12) and hence, there exists a unique steady state equilibrium.

Theorem 1. Assume that $G_{f}(x)$ and $G_{m}(y)$ have the same support $[0, x m a x]$. Assume further that there exists a constant $C<\frac{1}{\overline{x y}}$ such that the distributions' densities $g_{f}$ and $g_{m}$ satisfy

$$
g_{f}(x) g_{m}\left(R_{\text {old }}^{f}(x)\right) \leq C
$$

for all $x \in[0, x \max ]$. Then there exists a unique equilibrium for the system formed by equations (11) and (12). This equilibrium will be an interior solution, that is, both men and women will marry either at age 1 or 2 with positive probability.

Outline of Proof. Define

$$
H(x)=T_{1}\left(T_{2}(x)\right)
$$

In Equations (14) and (15) we show that every steady state equilibrium of the model corresponds to a fixed point of $H($.$) . A long calculation, relegated to the$ Appendix, shows that under the hypothesis of the theorem

$$
\left|H^{\prime}(x)\right|<1
$$


Consequently, $H(x)$ is a contraction mapping.

By the contraction mapping theorem, there exists a unique fixed point of $H($.$) .$ Call it $R_{\text {old }}^{m}$. A short argument in the Appendix shows that $R_{\text {old }}^{m} \in[0, x \max )$, and the associated $R_{\text {old }}^{f} \in[0, x \max )$, and that the uniqueness is ensured for $R^{m}$ and $R^{f}$. We conclude that the unique fixed point of $H($.$) corresponds to a steady state$ equilibrium of the model.

Remark 2. The hypothesis of Theorem 1 is trivially satisfied if $G_{f}(x)$ and $G_{m}(y)$ are uniformly distributed with support $[0,1]$

Proposition 3. Assume that the distributions of men and women are equal. Provided that people derive utility for having children within marriage $(k>1)$, then men will be choosier than women, that is, $R^{m}>R^{f}$.

Proof. See Appendix

\subsubsection{Stock of Singles in the Market}

Given the existence of an equilibrium, we can characterize the steady state number of single men and women using equations (2), (3), (8),(10), (11) and (12). The number of man and women that marry at the young age is

$$
\begin{aligned}
& h_{1}=m_{1} \phi_{1} \\
& w_{1}=f_{1} \gamma_{1}
\end{aligned}
$$

respectively, leaving the number of remaining (old) singles in the market as

$$
\begin{aligned}
m_{2} & =m_{1}-h_{1}=m_{1}\left(1-\phi_{1}\right) \\
f_{2} & =f_{1}-v_{1}=f_{1}\left(1-\gamma_{1}\right)
\end{aligned}
$$

In the same way, given the probabilities of marrying for old people are

$$
\begin{aligned}
& \phi_{2}=\left(\alpha_{2}^{\text {young }}+\alpha^{\text {old }}\right) \text { for men and } \\
& \gamma_{2}=\left(\lambda_{2}^{\text {young }}+\lambda^{\text {old }}\right) \text { for women }
\end{aligned}
$$

the number of people who marry when old are

$$
\begin{aligned}
& h_{2}=m_{2} \phi_{2}=m_{1}\left(1-\phi_{1}\right) \phi_{2} \\
& w_{2}=f_{2} \gamma_{2}=f_{1}\left(1-\gamma_{1}\right) \gamma_{2}
\end{aligned}
$$




\subsection{Example: Uniform Distribution}

In order to gain further intuition on the model, in this section we will solve the model assuming that the distribution of men and women of ages 1 or 2 is uniform with support $[0,1]$. That is:

$G_{f}(x)=G_{m}(y) \sim U[0,1]$

With this specification, the unique equilibrium is:

$$
\begin{aligned}
R^{m} & =\frac{1}{k(1+\beta)\left(4-p q \eta^{m} \beta^{2} \eta^{f}\right)} \eta^{m} \beta\left[2+p\left(2(k-1)-\beta \eta^{f}\right)\right] \\
R_{\text {old }}^{m} & =\frac{1}{\left(4-p q \eta^{m} \beta^{2} \eta^{f}\right)} \eta^{m} \beta\left[2+p\left(2(k-1)-\beta \eta^{f}\right)\right] \\
R^{f} & =\frac{1}{k(1+\beta)\left(4-p q \eta^{m} \beta^{2} \eta^{f}\right)} \eta^{f} \beta\left[2-q \eta^{m} \beta(1+p(k-1))\right] \\
R_{\text {old }}^{f} & =\frac{1}{k\left(4-p q \eta^{m} \beta^{2} \eta^{f}\right)} \eta^{f} \beta\left[2-q \eta^{m} \beta(1+p(k-1))\right]
\end{aligned}
$$

Equations (19) and (20) can be solved numerically in order to find the steady state equilibrium of the model. Figure 1 show the equilibrium values of selected variables as a function of $k \in[1,2]$, considering the following values for the parameters:

$$
\theta=0.5 \quad \beta=0.9 \quad \mu=0.9 \quad m_{1}=f_{1}=100
$$

Figure 1 shows how the reservation values of men and women, the fraction of single men (women) who are young, the probability of marriage at Age 1 and the ratio Single Men/Single Women change with the value of children $(k)$. As shown, the higher the increase in the utility of marriage for having children, the lower the reservation values for women, and the higher the probability that a woman marry young. Because women marry younger, the fraction of young women over the total of single women is increasing with $k$. On the other hand, men's behavior is the opposite to the one of women but the patterns seem to be relatively more stable. Therefore, the predictions of this simple 2-period model are the following:

- The higher the value of having children within marriage, women tend to marry younger and men older. For that reason, the age difference in marriage tend to increase with higher values of $k$. 


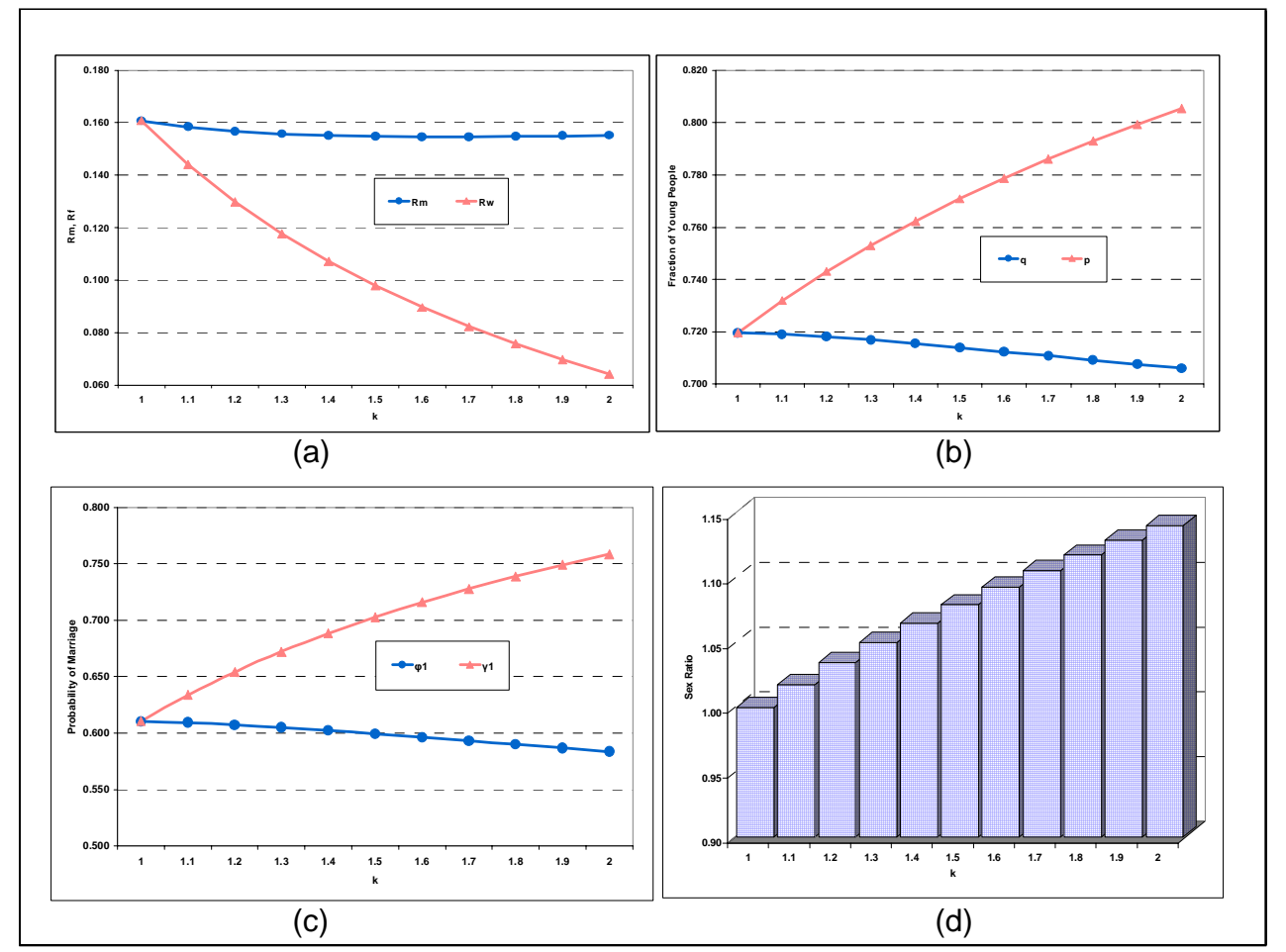

Figure 1: Equilibrium of the 2 Period Model for Different Values of $k$. Top: (a) Reservation Values, (b) Fraction of Young Men and Women, Bottom: (c) Probability of Marriage at Age 1, (d) Ratio Single Men/Single Women

- Single women in the marriage market tend to be younger than single men. That is, a given man is more likely to meet a young woman than is a woman to meet a young man.

- As their reservation values decrease with higher values of $k$, match qualities for women also tend to decrease.

\section{A Generalized Model}

In this section we extend the simple two period model to a more general finite horizon model. This general model is solved numerically. The following are the modified assumptions: 
Both men and women live $T$ periods. Women are fertile for $L$ periods, men are fertile for $N$ periods, with $L \leq N \leq T$. While women's fecundity decrease linearly form period $L_{1}$ to $L$, men keep their full fecundity until they lose it completely at period $N$.

As in the two period model above, women will meet at most one man per period and vice versa. The probability of meeting is determined by equations (2) and (3) .

As before, an exogenous flow of single young people of age $1, f_{1}$ women and $m_{1}$ men enter the market each period and the men and women who do not marry will remain in the market. Hence, the total number of single women and men will be the sum of the stock of single men and single women ages $i$ and $j$ respectively, $i, j \in[1, T]$

$$
\begin{aligned}
M & =\sum_{j=1}^{T} m_{j} \\
F & =\sum_{i=1}^{T} f_{i}
\end{aligned}
$$

Therefore, the fraction of single and men and women of ages $i, j$ will be

$$
\begin{aligned}
p_{i} & =\frac{f_{i}}{F} \\
q_{j} & =\frac{m_{j}}{M}
\end{aligned}
$$

which are endogenously determined.

We redefine the extra utility for having children for a man who marries at age $j$ with a woman of age $i$ as $k_{j i}^{m}$ where

$$
k_{j i}^{m}=\left\{\begin{array}{lc}
k & \text { if } j \leq N \text { and } i \leq L_{1} \\
k-\frac{(k-1)\left(i-L_{1}\right)}{\left(L+1-L_{1}\right)} & \text { if } L_{1}<i \leq L \text { and } j \leq N \\
1 & \text { otherwise }
\end{array}\right.
$$

Similarly, for a woman of age $i$ who marries a man of age $j$,

$$
k_{i, j}^{f}=\left\{\begin{array}{lc}
k & \text { if } i \leq L_{1} \text { and } j \leq N \\
k-\frac{(k-1)\left(i-L_{1}\right)}{\left(L+1-L_{1}\right)} & \text { if } L_{1}<i \leq L \text { and } j \leq N \\
1 & \text { otherwise }
\end{array}\right.
$$


where $k>1$ and is subject to the condition established in (5).

Given that the number of periods will be large enough in order to calibrate the results of the model with census data by age, it will be convenient to relax the assumption that people die only in the last period. For that reason we introduce a probability of dying each period that depends on the agent's age. The probability of dying in a given period for women and men of ages $i, j$ will be

$$
\begin{gathered}
d_{j}^{m} \quad \text { for a man of age } j<T \\
d_{i}^{f} \text { for a woman of age } i<T \\
d_{T}^{m}=d_{T}^{f}=1
\end{gathered}
$$

In the same way, the probability of that the marriage ends in a given period because of death will depend on the ages of husband and wife, as follows

$$
\Delta_{i, j}=d_{i}^{f}\left(1-d_{j}^{m}\right)+\left(1-d_{i}^{f}\right) d_{j}^{m}+d_{i}^{f} d_{j}^{m}
$$

The characteristics of the utility functions for men and women remain as in the model of the previous section.

\subsection{The Man's Optimization Problem}

Each period a man of age $j$ will meet a woman of age $i$ with probability $\eta^{m} p_{i}$ (by equations (3) and (21)). The probability of being accepted by that woman depends on the age of both the man and the woman. A man of age $j$ will receive an offer from a woman of age $i$ with probability

$$
\alpha_{j, i}=\eta^{m} p_{i}\left(1-G_{m}\left(R_{i, j}^{f}\right)\right)
$$

where $R_{i, j}^{f}$ will be the reservation value that a woman of age $i$ set for a man of age $j$.

Then the probability that a man of age $j$ has a concrete concrete opportunity of marriage will be

$$
\alpha_{j}=\sum_{i=1}^{T} \alpha_{j, i}=\sum_{i=1}^{T} \eta^{m} p_{i}\left(1-G_{m}\left(R_{i, j}^{f}\right)\right)
$$




\subsubsection{Expected Utility of Marrying at age $j$}

The expected utility that a man of age $j$ derives from marrying a woman of age $i$ depends on both the man's age and the woman's age. This occurs not only because fecundity matters, but also because the age of each partner will determine how long they will enjoy each other company. Consider first a man of age $j$ where $j \leq L_{1}$ (a fertile man such that a woman of the same age is still completely fertile). In this case he will be indifferent between any woman his age or younger because he will spend with her the rest of his life. If he marries an older woman, he will survive her and receive zero utility from the moment he become a widower until his own death. The case of an infertile $(j>N)$ man is similar, because the only utility of marriage is derived from the quality of the match and the length of the marriage. In the case that $L_{1}<j \leq N$ (a fertile man who is older than the age at which women start losing fecundity), a man will not be indifferent between any woman younger than himself because he will receive extra utility from a fully fertile spouse. Therefore, the expected utility of a man of age $j$ who marries a woman of age $i$ will be the discounted sum of the flows of expected payoffs of marriage through the length of the marriage. That is,

$$
u_{j, i}^{m}=\sum_{s=0}^{\operatorname{Min}(T-i, T-j)} \beta^{s}\left(1-\Delta_{i+s, j+s}\right) k_{j, i}^{m} \int_{R_{j, i}^{m}}^{x \max } x g_{f}(x) d x
$$

Given that the probability of a marriage offer from women of different ages differ, the expected utility of marrying at age $j$ will be

$$
\begin{aligned}
U_{j}^{m} & =\sum_{i=1}^{T} \alpha_{j, i} u_{j, i}^{m} \\
& =\sum_{i=1}^{T} \alpha_{j, i} \sum_{s=0}^{\operatorname{Min}(T-i, T-j)} \beta^{s}\left(1-\Delta_{i+s, j+s}\right) k_{j, i}^{m} \int_{R_{j, i}^{m}}^{x m a x} x g_{f}(x) d x
\end{aligned}
$$

\subsubsection{Probabilities of Marriage for Men}

Now we define the hazard rate for a man to marry at age $j$, as follows

$$
\phi_{j}=\sum_{i=1}^{T} \alpha_{j, i}\left(1-G_{f}\left(R_{j, i}^{m}\right)\right)
$$


Therefore, the unconditional probability that a man marries at age $j$ as

$$
\Phi_{j}=\phi_{j} \prod_{t=1}^{j-1}\left(1-\phi_{t}\right)
$$

\subsubsection{Objective Function for Men}

Given Equations (25) and (26), the objective function for any man at a given age $j$ is the following

$$
\sum_{j=t}^{T} \beta^{j-t} U_{j}^{m} \prod_{s=t+1}^{j}\left(1-d_{s-1}^{m}\right)\left(1-\phi_{s-1}\right)
$$

The Bellman Equation for the problem above is

$$
\begin{gathered}
V_{j}^{m}=\operatorname{Max}_{D_{j}^{m}}\left[U_{j}^{m}+\left(1-d_{j}^{m}\right)\left(1-\phi_{j}\right) \beta V_{j+1}^{m}\right] \\
V_{T}^{m}=\sum_{i=1}^{T} \alpha_{T i} k_{T, i}^{m} \int_{0}^{x m a x} x g_{f}(x) d x \\
D_{j}^{m}= \begin{cases}1 & \text { if } x>R_{j, i}^{m} \\
0 & \text { otherwise }\end{cases}
\end{gathered}
$$

where $D_{j}^{m}$ is the decision of marrying at age $j$ with a woman of age $i$.

\subsubsection{Men's Reservation Values}

The Reservation Values set by men can be obtained recursively given that

$$
R_{j, i}^{m}\left(\sum_{s=0}^{\operatorname{Min}(T-i, T-j)} \beta^{s}\left(1-\Delta_{i+s, j+s}\right) k_{j, i}^{m}\right)=\beta V_{j+1}^{m} \text { if } 1 \leq j \leq T-1
$$

The reservation value that a man of age $j$ sets for a given woman of age $i$ is

$$
R_{j, i}^{m}=\left\{\begin{array}{lc}
\frac{\beta V_{j+1}^{m}}{\left(\sum_{s=0}^{M i n(T-i, T-j)} \beta^{s}\left(1-\Delta_{i+s, j+s}\right) k_{j, i}^{m}\right)} & \text { if } 1 \leq j \leq T-1 \\
0 & \text { if } j=T
\end{array}\right.
$$




\subsubsection{Stocks of Single and Married Males}

The stocks of singles of age $j$ will be equal to the surviving singles of age $j-1$ who did not married during the last period. That is

$$
m_{j}=m_{j-1}\left(1-d_{j}^{m}\right)\left(1-\phi_{j-1}\right)
$$

Similarly to the 2-period Model (see Equation (17)), the total men who marry at age $j$ will be

$$
h_{j}=m_{j} \phi_{j}
$$

and the stock of married men of age $j$ will be the sum of the surviving males who married at age $j$ or younger. That is,

$$
H_{j}=\sum_{t=1}^{j} h_{t} \prod_{s=t}^{j-1}\left(1-d_{s}^{m}\right)
$$

\subsection{The Woman's Optimization Problem}

Each period a woman of age $i$ will meet a man of age $j$ with probability $\eta^{f} q_{j}$ (by Equations(2) and (22)). As above, the probability of being accepted by that bachelor will depend on the age of both of the woman and the man she meet. The probability that the woman of age $i$ receives an offer from a man of age $j$ is

$$
\lambda_{i, j}=\eta^{f} q_{j}\left(1-G_{f}\left(R_{j, i}^{m}\right)\right)
$$

where $R_{j, i}^{m}$ will be the reservation value that a man of age $j$ set for a woman of age $i$.

The probability of receiving an offer from any man at age $i$ will be

$$
\lambda_{i}=\sum_{j=1}^{T} \lambda_{i, j}=\sum_{j=1}^{T} \eta^{f} q_{j}\left(1-G_{f}\left(R_{j, i}^{m}\right)\right) .
$$




\subsubsection{Expected Utility of Marrying at age $i$}

In the same way as for men, the expected utility that a woman of age $i$ derives from marrying a man of age $j$ depends on the expected length of the marriage

$$
u_{i, j}^{f}=\sum_{s=0}^{\operatorname{Min}(T-i, T-j)} \beta^{s}\left(1-\Delta_{i+s, j+s}\right) k_{i, j}^{f} \int_{R_{i, j}^{f}}^{\operatorname{ymax}} y g_{m}(y) d y
$$

and her expected utility of marrying at age $i$

$$
\begin{aligned}
U_{i}^{f} & =\sum_{j=1}^{T} \lambda_{i, j} u_{i j}^{f} \\
& =\sum_{j=1}^{T} \lambda_{i, j} \sum_{s=0}^{\operatorname{Min}(T-i, T-j)} \beta^{s}\left(1-\Delta_{i+s, j+s}\right) k_{i, j}^{f} \int_{R_{i, j}^{f}}^{\operatorname{ymax}} y g_{m}(y) d y
\end{aligned}
$$

\subsubsection{Probabilities of Marriage for Women}

The hazard rate of marriage for a woman at age $i$ is defined as

$$
\gamma_{i}=\sum_{j=1}^{T} \lambda_{i, j}\left(1-G_{m}\left(R_{i, j}^{f}\right)\right)
$$

and the unconditional probability that a woman marries at age $i$

$$
\Gamma_{i}=\gamma_{i} \prod_{t=1}^{i-1}\left(1-\gamma_{t}\right)\left(1-d_{t}^{f}\right)
$$

\subsubsection{Objective Function for Women}

Given Equations (32) and (33), the objective function of a single woman at age $i$ is the following

$$
\sum_{i=t}^{T} \beta^{j-t} U_{i}^{f} \prod_{s=t+1}^{i}\left(1-d_{s-1}^{f}\right)\left(1-\gamma_{s-1}\right)
$$


As is the case of the man above, the Bellman Equation for the woman's problem is then

$$
\begin{gathered}
V_{i}^{f}=\underset{D_{i}^{f}}{\operatorname{Max}}\left[U_{i}^{f}+\left(1-d_{i}^{f}\right)\left(1-\gamma_{i}\right) \beta V_{i+1}^{f}\right] \\
V_{T}^{f}=\sum_{j=1}^{T} \lambda_{T j} \int_{0}^{y \max } y g_{m}(y) d y \\
D_{i}^{f}=\left\{\begin{array}{cc}
1 & \text { if } y>R_{i, j}^{f} \\
0 & \text { otherwise }
\end{array}\right.
\end{gathered}
$$

where $D_{i}^{f}$ is the decision of marrying at age $i$ with a man of age $j$.

\subsubsection{Reservation Values for Women}

As in the case for men, the reservation values for women can be obtained recursively. Given that

$$
R_{i, j}^{f}\left(\sum_{s=0}^{\operatorname{Min}(T-i, T-j)} \beta^{s}\left(1-\Delta_{i+s, j+s}\right) k_{i, j}^{f}\right)=\beta V_{i+1}^{f} \quad \text { if } \quad 1 \leq i \leq T-1
$$

The reservation value for a woman of age $i$ with respect to a man of age $j$ will be

$$
R_{i, j}^{f}=\left\{\begin{array}{lr}
\frac{1}{\left(\sum_{s=0}^{M i n(T-i, T-j)} \beta^{s}\left(1-\Delta_{i+s, j+s}\right) k_{i, j}^{f}\right)} \beta V_{i+1}^{f} & \text { if } 1 \leq i \leq T-1 \\
0 & \text { if } i=T
\end{array}\right.
$$

\subsubsection{Stocks of Single and Married Females}

Similarly to the previous case, we define the number of single women of age $i$ as follows

$$
f_{i}=f_{i-1}\left(1-d_{i-1}^{f}\right)\left(1-\gamma_{i-1}\right) .
$$

The total of women who marry at age $j$ will be

$$
w_{i}=f_{i} \gamma_{i}
$$


As for men, the stock of married women of age $i$ is

$$
W_{i}=\sum_{t=1}^{i} w_{t} \prod_{s=t}^{i-1}\left(1-d_{s}^{f}\right)
$$

\subsection{Numerical Solution}

Now we can solve numerically the system formed by Equations (28), (29), (35) and (36). The distribution functions $G_{f}(x)$ and $G_{m}(y)$ are both uniform with support $[0,1]$ and the values given to the parameters will be the following ${ }^{16}$ :

$$
\begin{array}{ll}
T=60(75 \text { years old }) & N=45(60 \text { years old }) \\
L_{1}=20(35 \text { years old }) & L=30 \quad(46 \text { years old }) \\
\mu=0.9 & k=1.3 \\
\beta=0.915 & \theta=0.5 \\
m_{1}=100 & f_{1}=100
\end{array}
$$

\subsubsection{Reservation Values and Marriage Offers}

Figure 2 shows the reservation values for men and women with respect to people of the opposite sex of the same age and Figure 3 shows the probability of receiving a marriage offer at each age (by Equations (23) and (31)). Interpreting both graphics will help to summarize several of the predictions of the model about marriage behavior.

As shown in Figure 2, women younger than age 34 set a higher reservation value than men of the same age. The reason for this is the traditional one: fertile women are outnumbered by fertile men. As in Siow (1998), a young woman faces relatively better market conditions than a man of her age. This is what has been emphasized by the literature. In principle there is a counter balancing force lowering the reservation values of women that is their relatively shorter fecundity horizon. However, for women in their late teens or early twenties the distant end of their fecundity years is sufficiently removed that the better marriage market conditions for women are large enough to make them more choosy than men.

When the decline in fecundity is nearer, the reservation values of women start to decrease sharply. In this example we assume that fecundity start to decline at age 36, and this causes the reservation value to start to decrease in the mid

\footnotetext{
${ }^{16}$ The Mortality data is obtained from the US Life Tables for whites for 1995.
} 


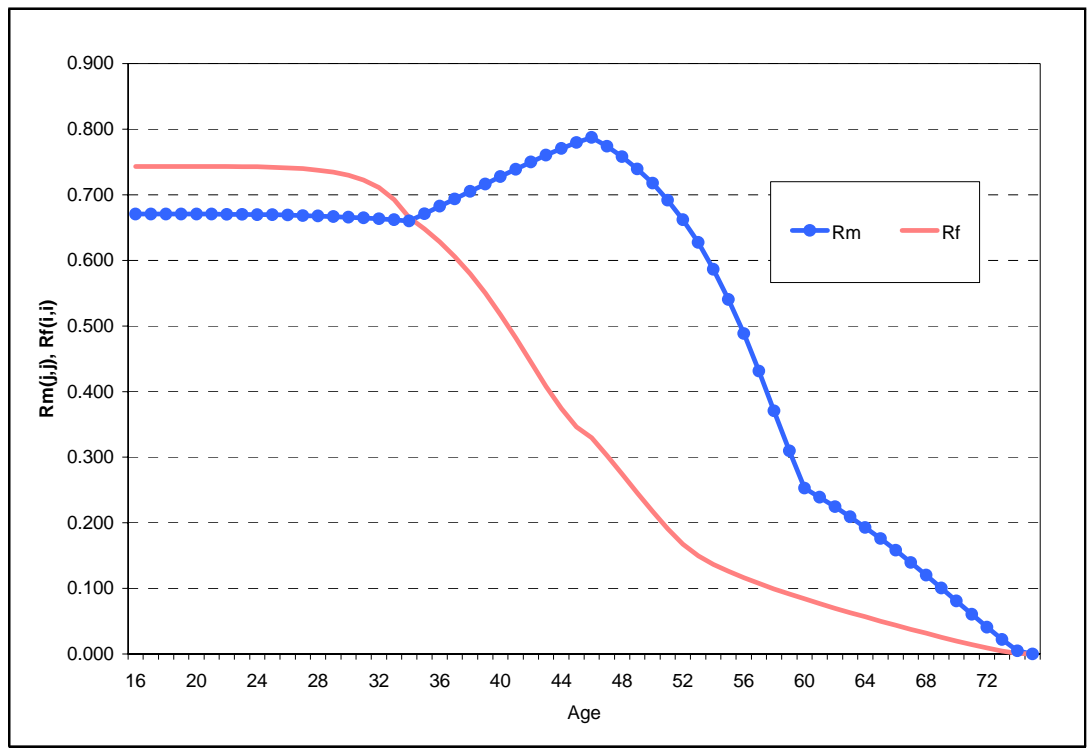

Figure 2: Reservation Values for Potential Spouses of the Same Age

twenties and continue through the end of their fertile years. Note that after fecundity ends, reservation values continue to decline. This however is driven by mortality as the shorter life expectancy is cause fewer chances to marry

The behavior of men is different than the one of women. The reservation value for men younger than age 34 is flat and lower than the one for women because, as stated above, fertile men outnumber fertile women. When women's fecundity start to decline around 35 years old, men of the same age raise their reservation value for those women in light of their increasing probability of being barren. Around age 50, the reservation values for men decrease sharply in light of the foreseeable loss of fecundity (in this example at age 60).

The behavior of men and women in this general model can be compared to the results established in the 2-period model. One of the principal results of the model was that women (in period 1) set a reservation value lower than the one set by men. This is because the 2-period model does not give women sufficient distance from the end of fecundity to take advantage of their relative scarcity at a point in time.

Figure 3 reflects how reservation values of men and women affect the opportunities of the other side of the market. In the case of women, the probability of 


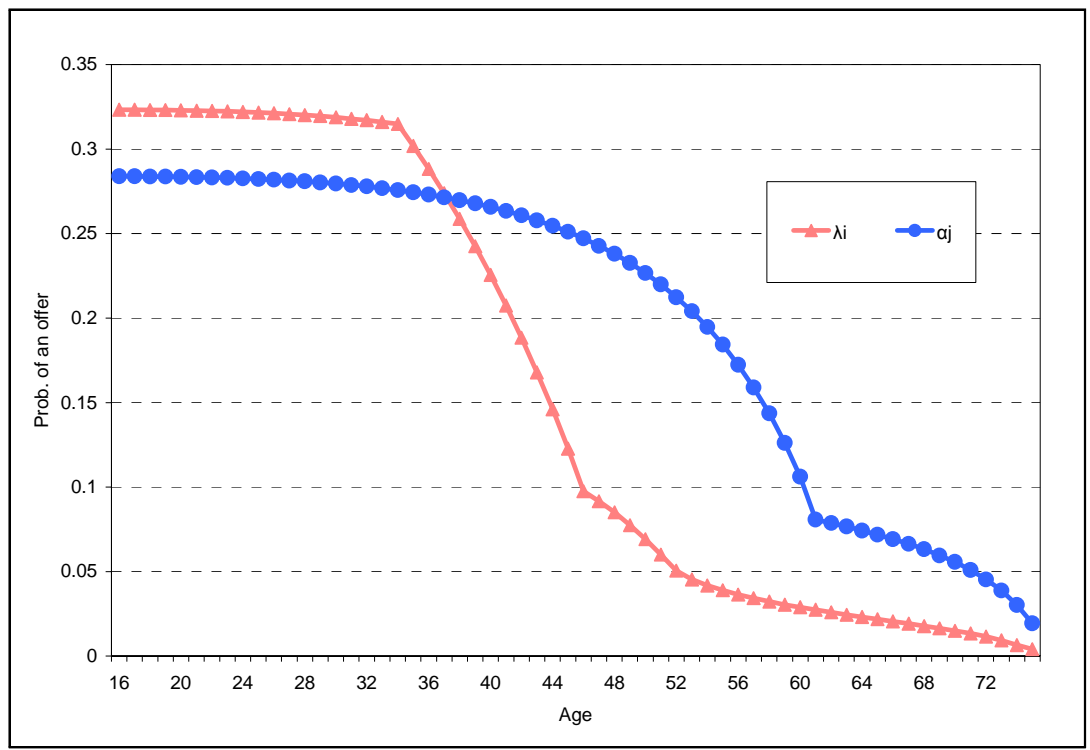

Figure 3: Probability of Receiving a Marriage Offer for Men $\left(\alpha_{j}\right)$ and Women $\left(\lambda_{i}\right)$

receiving a marriage offer drops when they are in their middle 30's (when fecundity starts to decline). Note that offers start to decline later than when reservation values begin to decline (at age 25). The reason for this is that the decline in offers from men to women is a function of men's reservation values. Women who are younger than 35 remain completely acceptable to men as they are still completely fertile. This occurs for two important but different reasons. First, women worry about their own ability to bare children and the utility they will receive for this. Second, women rationally anticipate their worsening position in the marriage market knowing that men will begin increasing their reservation value for women over 35 as younger women will remain as a viable substitute. For men, the probability of receiving a marriage offer decreases at an increasing rate between ages 35 and 60.

\subsubsection{Hazard Rates}

Figure 4 shows the hazard rates of marriage for men and women at each age. Observe that there is a sharp increase in the probability that single women marry from their late 20's to their middle 30's. That increase is due to lower women's 
reservation values as the decline in fecundity is approaching. Assuming that fecundity starts to decline at age 35, the figure shows how the hazard rate for women increase at a diminishing rate from 35 to 40 and then decrease trough the end of her life. As women's fecundity declines, men are more reluctant to marry them due to the increasing risk of not having a child (observe in Figure 2 how men from 35 to 46 increase their reservation value for women of the same age). When women lose fecundity completely (here at age 47), notice the kink in the hazard rate curve. The explanation for this is that a new market appears: infertile women are now much less choosy about marrying infertile men.

The pattern of the hazard rates for men is similar to that of women, but the timing is different. As the reservation values of men decrease with time, their hazard rates for marriage are increasing through their fertile period (until 60 years old).Thereafter the reservation values decrease sharply. Then, as infertile women become acceptable, the drop stops to then continue as a slower pace during the last few years of their life.

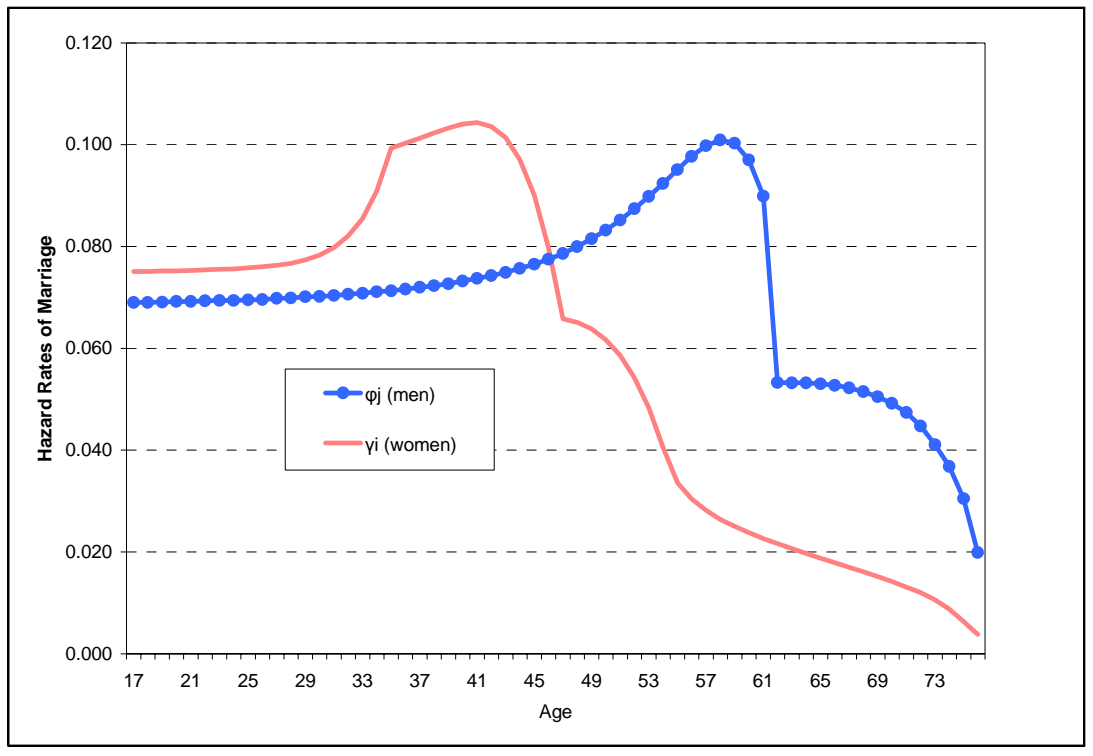

Figure 4: Hazard rates of Marriage for Men $\left(\phi_{j}\right)$ and Women $\left(\gamma_{i}\right)$

\subsubsection{Stocks of Men and Women by Marital Status}


Figure 5 shows the stocks of single men, single women, married men (by Equation (30)) and married women (Equation (37)) at each age. The actual pattern of the 2000 US census data (whites) is displayed in Figure 6. Note that single men outnumber single women from their early 20 's until near age 60 , and that the number of married women is greater than the number of married men in most of the life cycle. The reason for this is that, since more women marry at a young age, this affects the stocks of people of all ages. One interesting feature of the model is that by age 55 the sex ratio of married men to married women approaches one, but before reaching parity the number of married men starts to decline more quickly than the number of married women. because men marry later than women, for to attain parity with women there must be ages at which men marry with higher probability than women. This does occur (after age 42) but the higher mortality rates of men offset the higher marriage rates leaving the stock of married women to be greater than the stock of married men.

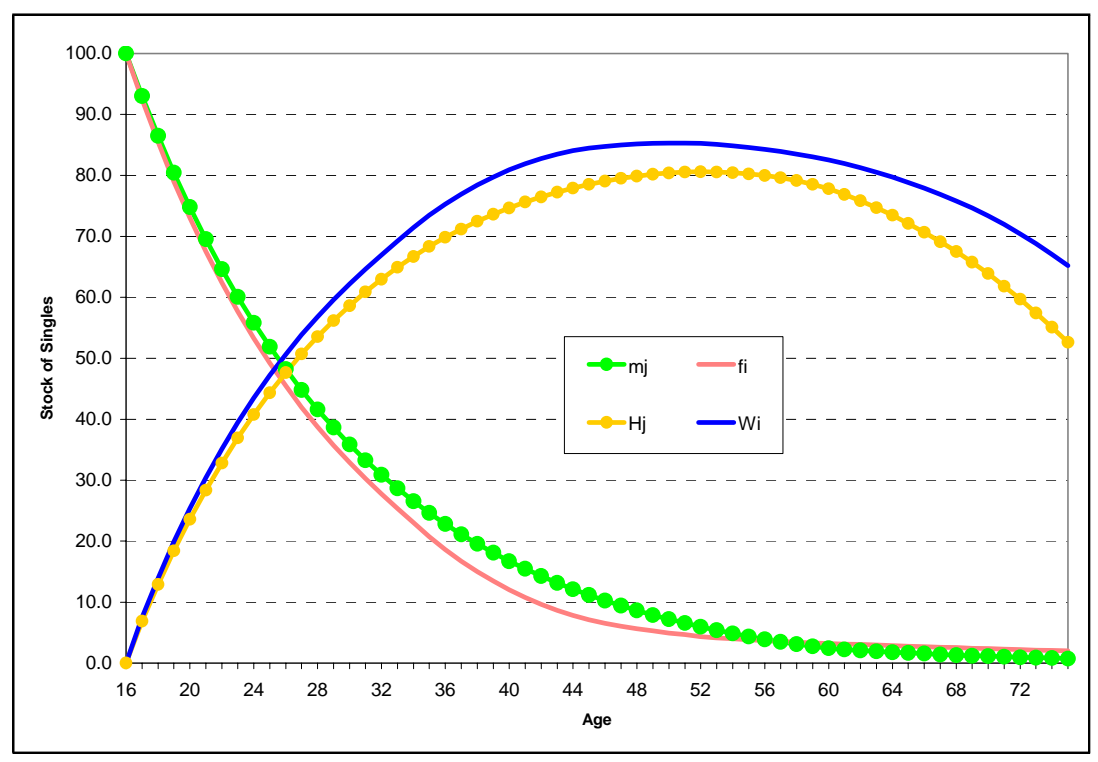

Figure 5: Stocks of Single Men $\left(m_{j}\right)$, Single Women $\left(f_{i}\right)$, Married Men $\left(H_{j}\right)$ and Married Women $\left(W_{i}\right)$ 


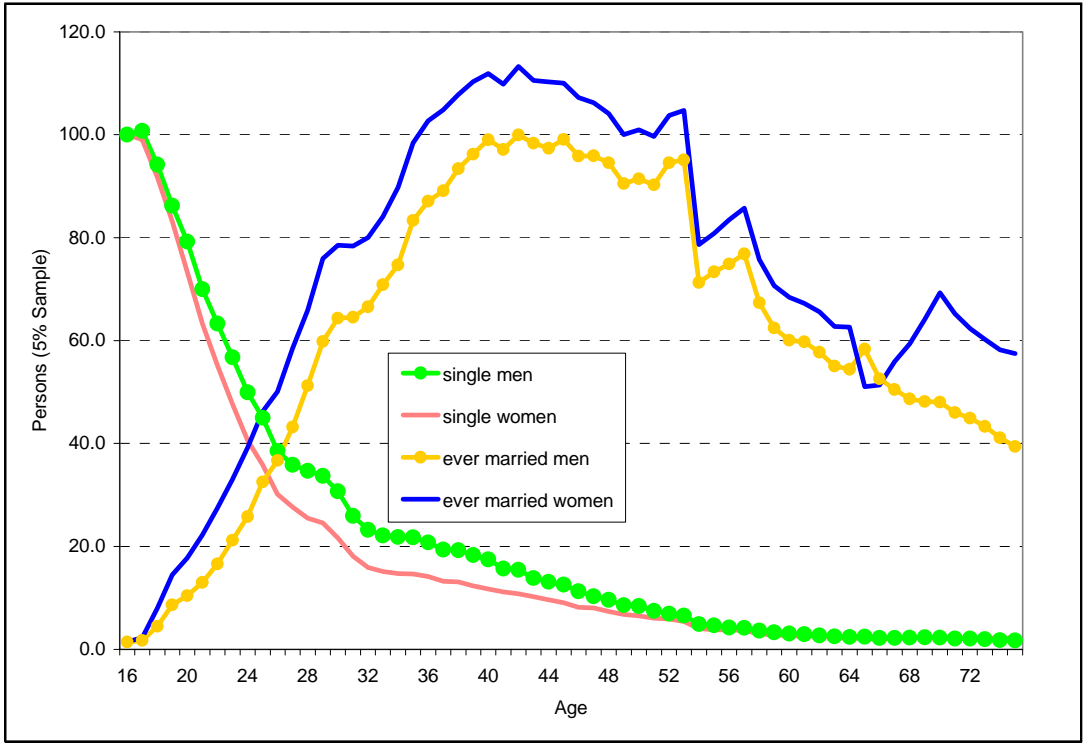

Figure 6: Stock of Single and Ever Married Men and Women in US Census 2000 (Whites - 5\% Sample)

\subsubsection{Comparative Statics}

This model has two key parameters -the value of having children within marriage, $k$ and the discount factor, $\beta$. Here we analyze how do the model predictions change with changes in these parameters. Figures 7 and 8 the comparative statics results on $k$ while Figures 9 and 10 show results for $\beta$. Take example for $k=1.1$, a low premium for having children within marriage; in this case we have that men marry at age 28 and women at 27.5. The pattern of the sex ratio is almost flat, with a small increase during the period of declining fecundity and then a more pronounced decline from mid 50's (due to higher male mortality rates). That is, if having children does not play a big role in the decision of marriage, the age difference tend to disappear, and the sex ratio of singles differs from parity only because differential mortality of men and women. As the value of having a family increases, men marry at older ages and women at younger ages. This causes the sex ratio to have an inverted U-shape that peaks during the decline in women's fecundity. One interesting case is what happen when $k=1$. As shown in Figure 7 , men marry on average younger than women. The sex ratio of singles is then decreasing during the entire life cycle (Figure 8 ). If $k=1$, it is only mortality that 


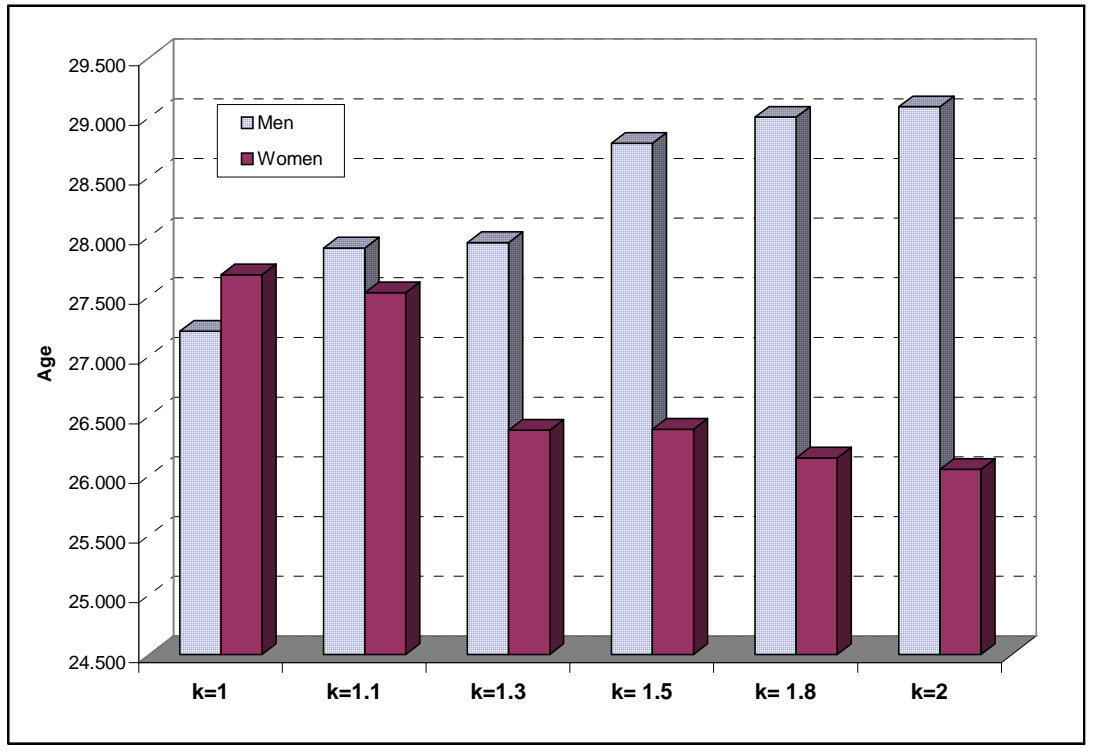

Figure 7: Average Age at Marriage for Different Values of $k(\beta=0.91)$

causes the sex ratio to differ from parity and cause any age difference at marriage between men and women. The higher male mortality causes a scarcity of men increasing the probability of an offer per period and improving their marriage prospects. Given that this solution is calculated with the mortality rates for whites in the U.S. in 1995, an even greater imbalance in young mortality between men and women (for example Blacks in the U.S.) could have a big effect on the composition of the marriage market and age at marriage for men and women.

Figures 9 and 10 show the age at marriage and the pattern of the sex ratio for singles at different values of $\beta$. As one can imagine, people tend to marry later when they are more patient (higher levels of $\beta$ ). Also, as shown in Figure 10, the sex ratio tends to be flatter for levels of $\beta$ within the usual range (0.90 to 0.99). However, what is striking is what happen at high discount rates ( Here again men marry younger than women and the sex ratio is decreasing at all ages. When people discount future utility heavily enough, the differential mortality rates between men and women, even when very small, cause men to marry younger than women (same effect as when children within marriage are not valuable). 


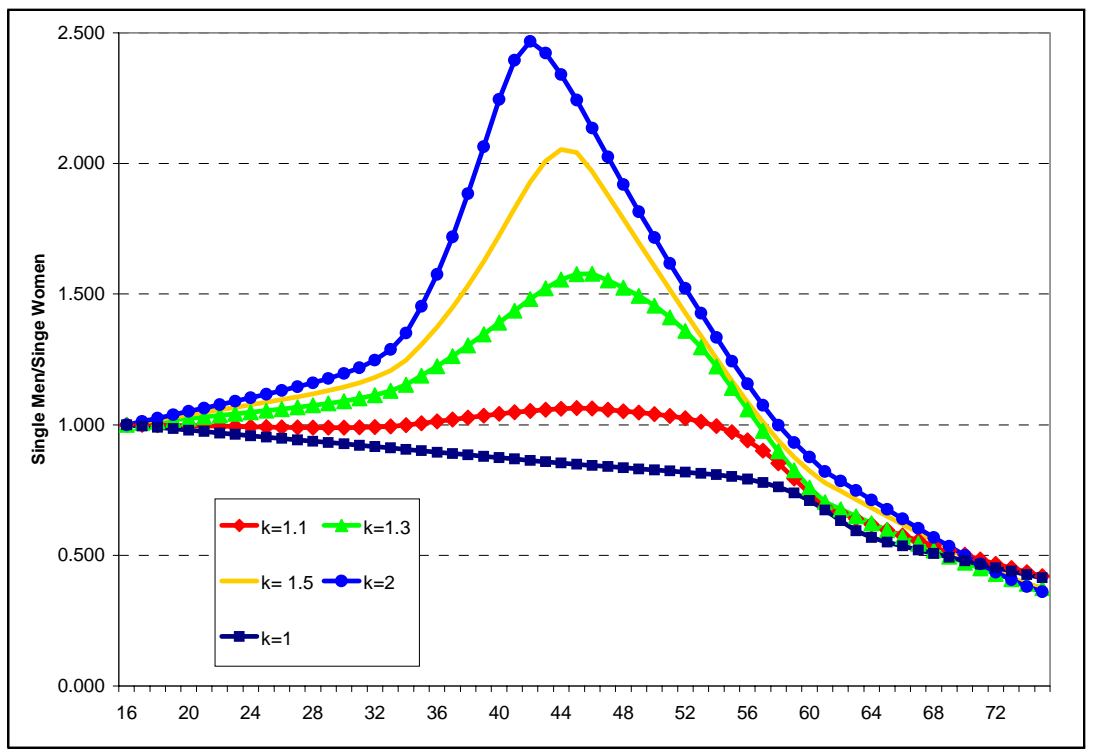

Figure 8: Ratio Single Men/Single Women by Age for Different Levels of $k$ $(\beta=0.91)$

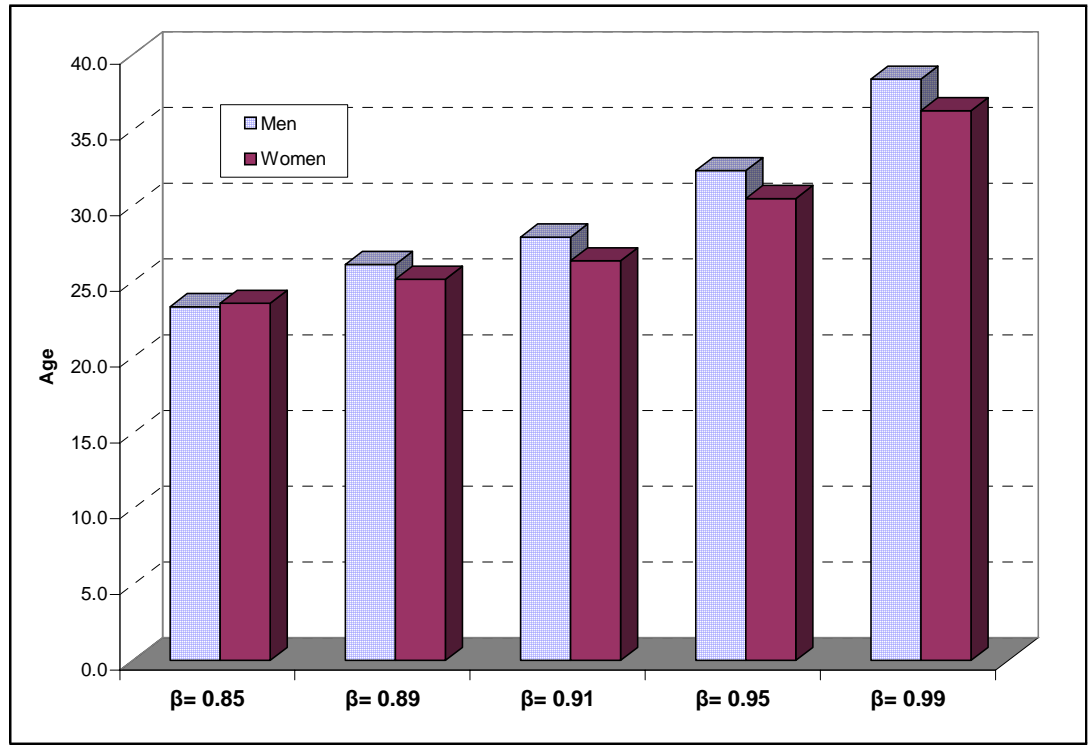

Figure 9: Average Age at Marriage for Different Values of $\beta(k=1.3)$ 


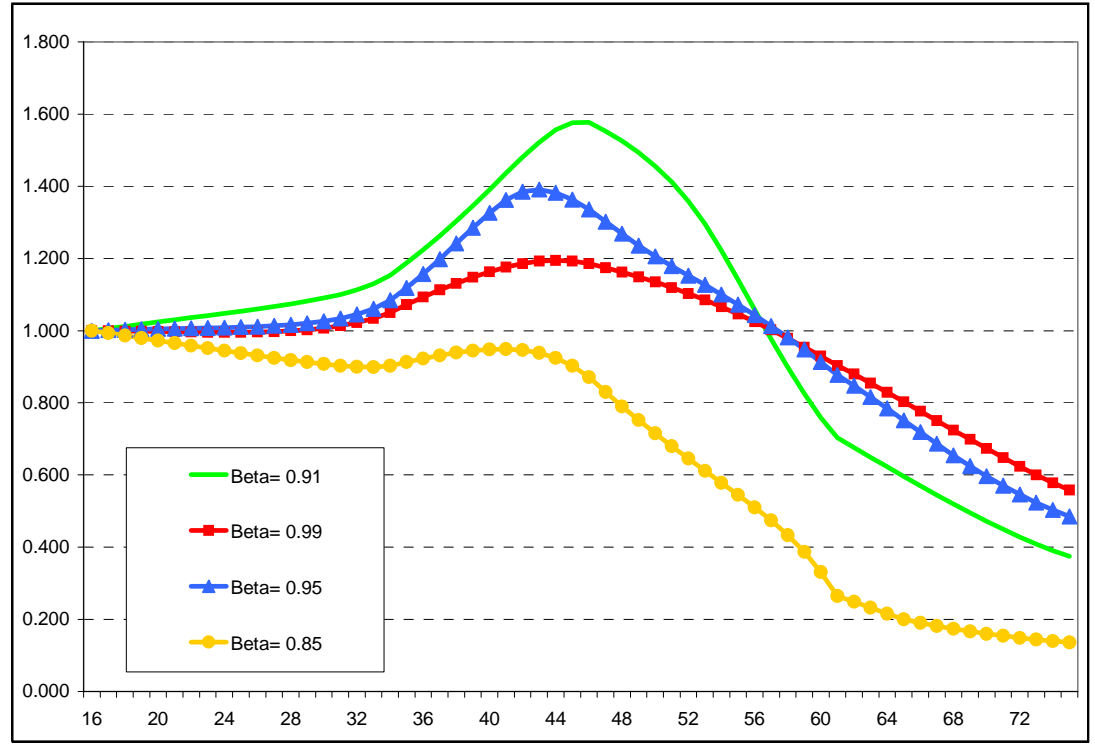

Figure 10: Ratio Single Men/Single Women by Age for Different Levels of $\beta$ $(k=1.3)$

\section{Comparison with Census Data}

\subsection{US Census 2000}

In order to compare the model results with US Census data two sources of data are used. The data on age at first marriage is from the 1995 Marriage Detail File (MDF) of the U.S. Vital Statistics Registry. ${ }^{17}$ For all other statistics the data is from the 2000 IPUMS 5\% data. People in institutions are excluded from the sample, and the analysis is limited to people born in the US. Despite pooling across cohorts, the fact that most marriages occur by age 40 minimizes that problem. Of particular interest is the different marriage markets for White and Black Americans. Therefore a separate analysis is conducted for Blacks and Whites.

\footnotetext{
${ }^{17}$ The Marriage Detail File has not been released since 1995 and is the closest data to the U.S Census 2000. The Census stopped asking age at first marriage in 1980.
} 


\subsubsection{Whites}

Figure 11 and Table 1 show a comparison between the model results and the data when $\beta=0.91$ and $k=1.3$. The model predicts men and women marrying later (men at age 27.9 and women at 26.3 years old compared with the actual 26.3 and 25.2 respectively). Also the model suggests a smaller age difference at first marriage (1.1 year versus 1.6 years in the data). Table 1 also displays a comparison between the model and the census data and MDF for the average age of singles and ever married, the ratio single men/single women, the fraction of ever married and widows/ers (only widows in the model) and the sex ratio of ever married. Figure 11 shows the pattern of the sex ratio by age for singles and ever married. Observe that the ratio single male/single female peaks at around age 40 in the data and around the assumed end of fecundity (age 47) in the model results.

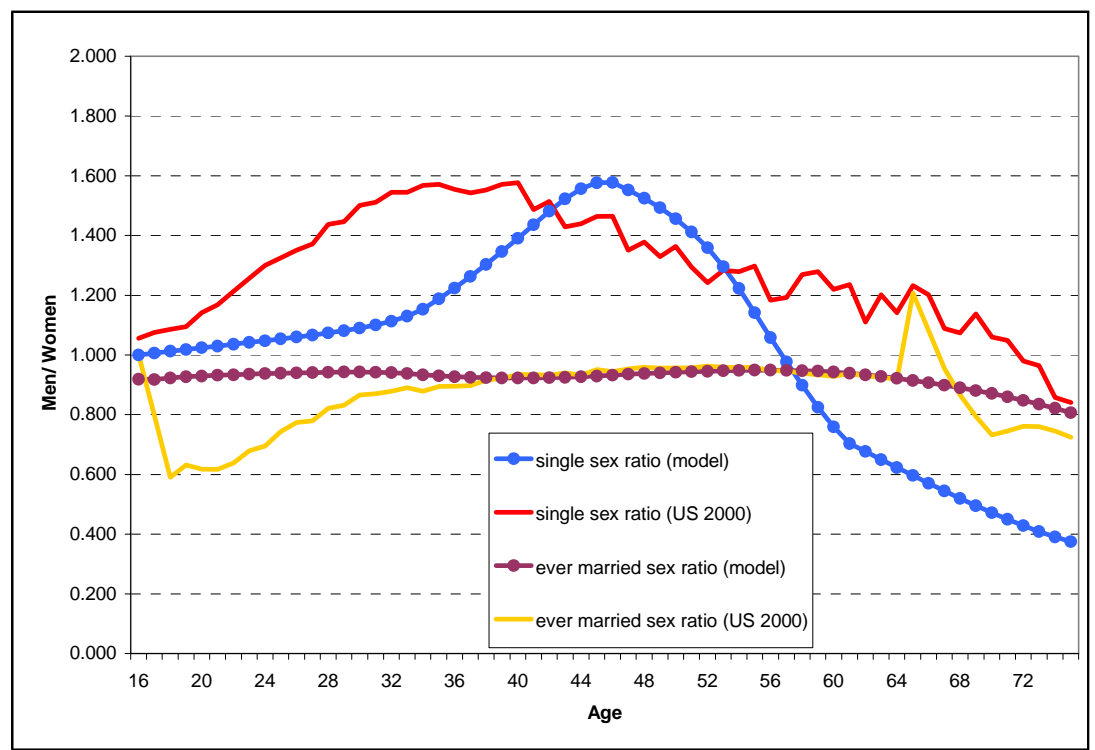

Figure 11: Sex Ratio for Single and Ever Married. US Census 2000 (Whites) and Model $(k=1.3, \beta=0.91)$ with mortality rates for whites.

\subsubsection{Blacks}

Figure 12 and Table 2 show a comparison between the model results and the census data when $\beta=0.93$ and $k=1.08$. This value of $k$ implies a low premium 


\begin{tabular}{|c|c|c|c|c|}
\hline & \multicolumn{2}{|c|}{$\begin{array}{c}\text { Model } \\
\text { (1) }\end{array}$} & \multicolumn{2}{|c|}{$\begin{array}{c}\text { US } 2000 \\
(2)\end{array}$} \\
\hline & Men & Women & Men & Women \\
\hline$\beta$ & \multicolumn{2}{|r|}{0.91} & & \\
\hline$k$ & \multicolumn{2}{|r|}{1.30} & & \\
\hline Age of First Marriage & 27.9 & 26.4 & 26.3 & 25.2 \\
\hline Average Age of Singles & 28.0 & 26.4 & 27.9 & 27.1 \\
\hline Sex Ratio of Singles & \multicolumn{2}{|r|}{1.08} & \multicolumn{2}{|r|}{1.25} \\
\hline Ever Married (\%) & 0.74 & 0.80 & 0.74 & 0.79 \\
\hline Fraction of Singles 45 and Over & 0.05 & 0.04 & 0.06 & 0.05 \\
\hline Fraction of Widows/ers & & 0.08 & 0.01 & 0.06 \\
\hline Average Age of Ever Married & 48.9 & 49.2 & 47.8 & 47.4 \\
\hline Sex Ratio for Ever Married & \multicolumn{2}{|r|}{0.92} & \multicolumn{2}{|r|}{0.90} \\
\hline Total Sex Ratio & \multicolumn{2}{|r|}{0.96} & \multicolumn{2}{|r|}{0.97} \\
\hline
\end{tabular}

Table 1: Comparison Between Model and US Census 2000 (Whites)

for having children within marriage $(k=1$ would imply people is indifferent with respect of having children out of wedlock). In this case while the model predicts very accurately the age at marriage for men (28.7 years versus 28.9 years in the data), the model predicts than women will marry 0.5 years later than in the data. (28.3 versus 27.8 years).

How important is differential mortality? What is particularly important in the model is the relative mortality of men and women in a racial group. Figure 13 shows the relative mortality rate for men versus women at each age. Notice that while the mortality rate of men is greater than the mortality rate of women for both Blacks and whites, the mortality rate for Black men relative to Black women is extremely large between ages 16 and $28 .{ }^{18}$

How does the higher mortality of Black men effect the marriage market equilibrium? To analyze this, Figure 14 shows the reservation values for Black men and women as well as white men and women at each age. Here the same parameter values apply to both races but each race is calculated according to their

\footnotetext{
${ }^{18}$ It is well known that the fraction of men in federal or state prison or local jails at these ages is also differentially high for Black men. Statistics from the Bureau if Justice Statistics suggest that approximately $9-12 \%$ of Black men between ages 18 and 29 are in federal or state prison or in a local jail. This would tend to reinforce the results discussed here.
} 


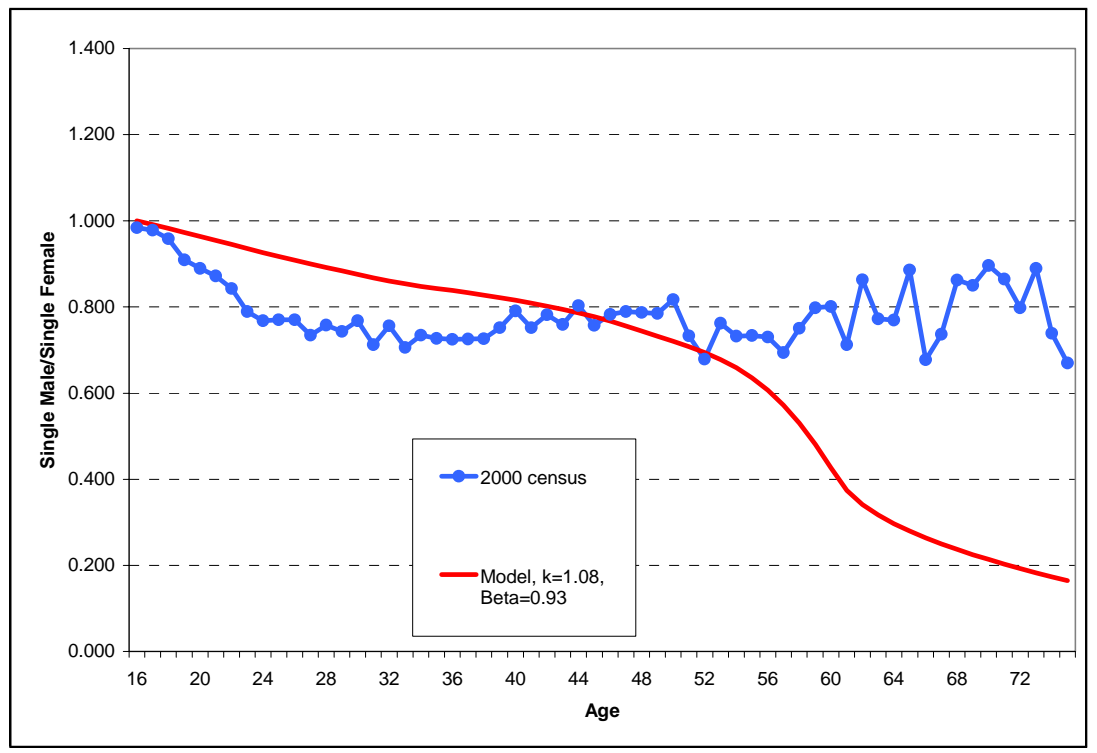

Figure 12: Ratio Single Males/Single Females. US Census 2000 (Blacks) and Model $(k=1.08, \beta=0.93)$ with mortality rates for blacks.

\begin{tabular}{|lcccc|}
\hline & \multicolumn{2}{c}{$\begin{array}{c}\text { Model } \\
\text { (1) }\end{array}$} & \multicolumn{2}{c|}{ US 2000 } \\
& Men & Women & Men & Women \\
\hline$\beta$ & \multicolumn{2}{c}{0.93} \\
$k$ & \multicolumn{2}{c}{1.08} & & \\
Age of First Marriage & 28.7 & 28.3 & 28.9 & 27.8 \\
Average Age of Singles & 27.8 & 29.6 & 28.9 & 29.7 \\
Sex Ratio of Singles & \multicolumn{2}{c}{0.91} & \multicolumn{2}{c|}{0.82} \\
Ever Married (\%) & 0.69 & 0.69 & 0.58 & 0.60 \\
Fraction of Singles Over 45 & 0.06 & 0.09 & 0.08 & 0.13 \\
Fraction of Widows/ers & & 0.11 & 0.02 & 0.08 \\
Average Age of Ever Married & 47.9 & 49.2 & 46.8 & 47.2 \\
Sex Ratio for Ever Married & & 0.89 & & 0.77 \\
Total Sex Ratio & & 0.90 & & 0.79 \\
& & & & \\
\hline
\end{tabular}

Table 2: Comparison Between Model and US Census 2000 (Blacks) 


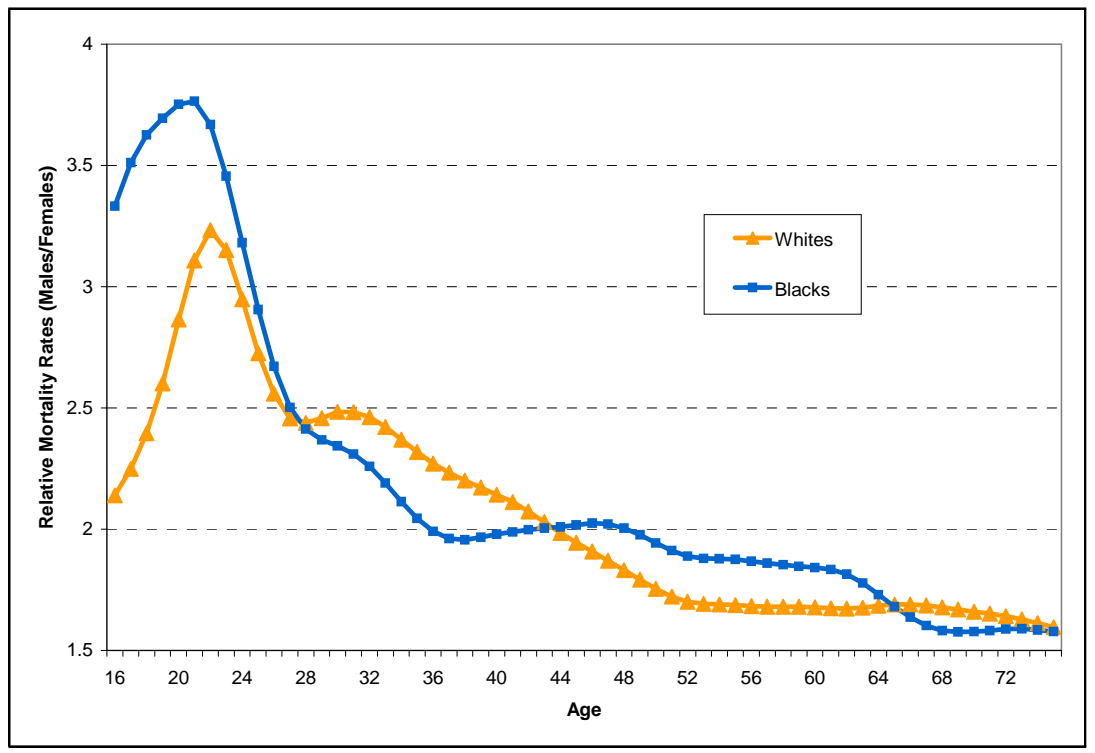

Figure 13: Relative Mortality Rates (Males/Females) for Blacks and Whites under Age 75

own race (and gender) specific mortality rates. In Figure 14 it is clear that unlike whites, where the reservation value for men is higher than for women only at older ages, for Blacks, the reservation value for men is higher than the reservation for women at all ages. That is, if children within marriage are not very valuable (relative to outside of marriage), then the relative scarcity of fertile women plays only a weak role in the market. Conversely, the higher mortality rates for Black men give them the bargaining power in the market. For that reason, Black men receive relatively more offers than women reducing their waiting time to marriage from what it would be with lower mortality. The net result is that Black men and women tend to marry around the same age.

Figure 15 shows that unlike for white Americans, the ratio of single men to single women falls below parity at all ages for Black men. Higher male mortality would seem to almost mechanically cause the sex ratio of single men to single women to fall below parity (because there are generally fewer men alive than women). However, white men also have higher mortality than white women. The mortality of white men is not sufficiently high relative to white women to offset the natural scarcity that young women enjoy because of women's fecundity 


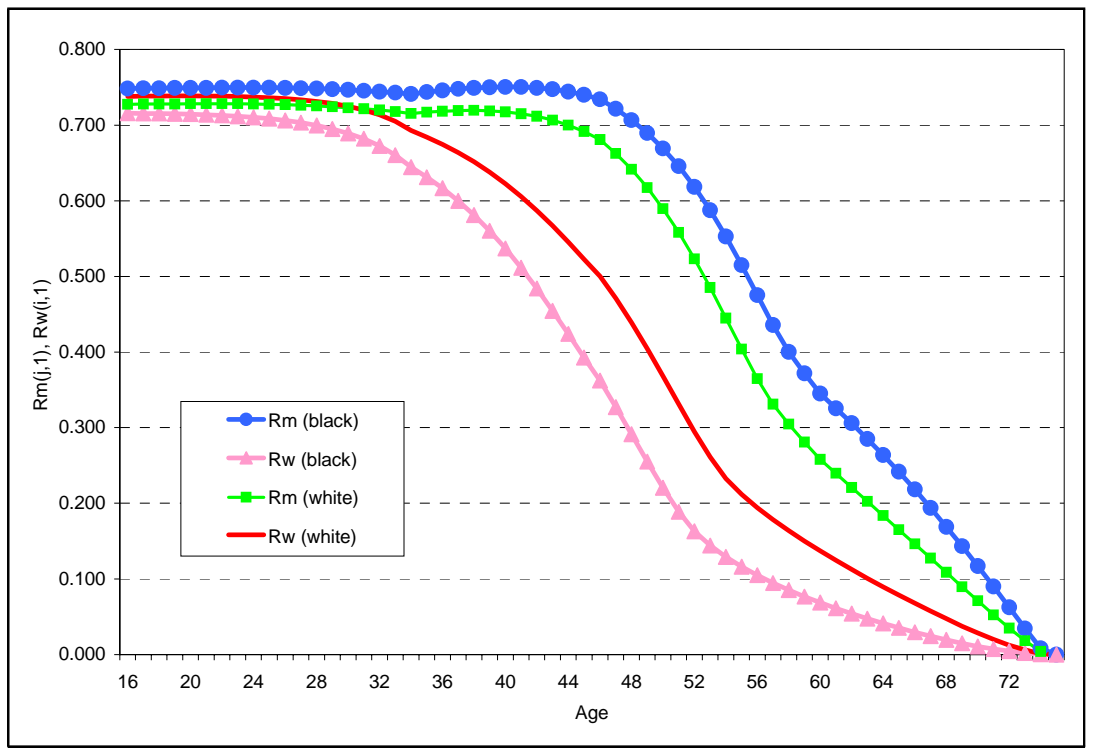

Figure 14: Reservation Values for Potential Spouses of the Same Age. Model with $k=1.08, \beta=.93$ and Mortality for Blacks and Whites in 1999.

is limited and children within marriage are valuable $(k>1)$. For whites, the scarcity of fertile women (driven by limited fecundity) dominates the scarcity of men (driven by differential mortality). Thus white women are choosier at young ages causing young men to wait to marry until the terms of trade change in their favor (as women's fecundity declines). Thus for whites, even though male mortality is greater than female mortality, the sex ratio of single men to single women remains above parity for much of the life cycle.

Blacks are different. Black women face the same scarcity producing effect of a limited fecundity horizon as white women. However, Black male mortality is sufficiently greater than Black female mortality to offset the natural scarcity women usually enjoy at young ages. With differentially high Black male mortality, it is men that are scarce over the entire life cycle. Thus Black men do not face the same incentives to delay marriage as they do not have growing scarcity over time (as do white men). For this reason, Black men and women marry at close to the same age and the fewer Black men that survive mortality end up driving the sex ratio below parity at all ages. Two factors play a role in making the sex ratios for Blacks decrease over the entire life cycle: First the higher mortality rates for 


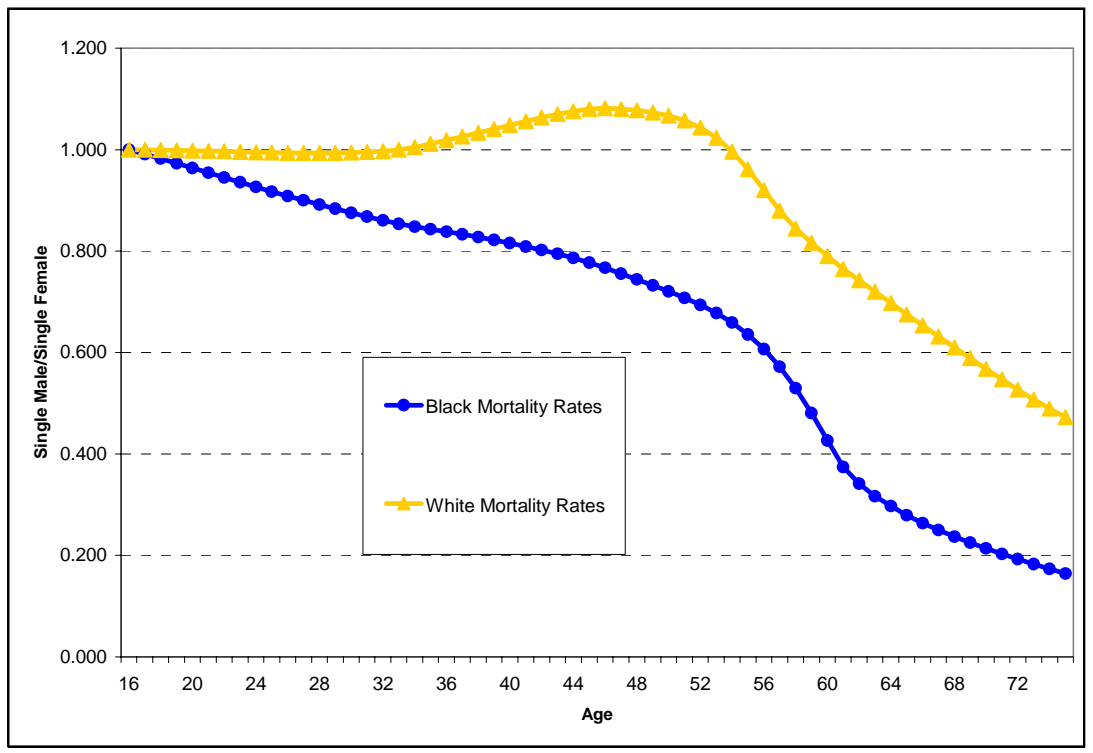

Figure 15: Ratio Single Men/Single Women. Model with $k=1.08, \beta=.93$ and Mortality for Blacks and Whites in 1999.

Black men and second, the fact that Black men do not wait more than women in order to marry.

The consequence of this behavior is that a larger fraction of Black women never marry. As shown in Tables 1 and 2, in 2000, 13\% of Black women aged 45 and over never married compared to only $5 \%$ of White women. The predictions of the model is qualitatively similar. However the fraction of women predicted never to marry are lower for both races (9\% for Blacks versus $5 \%$ for Whites) ${ }^{19}$

This finding is related to the Wilson Hypothesis, although the mechanism leading to lower marriage rates is different. Wilson's model is typically interpreted as Black women rejecting Black men (who have made offers) because they do not bring enough to the marriage (i.e. are not "marriageable" because of poor job prospects). In my model Black women also delay marriage (or do not marry) but it is because men reject women. Men reject women because the higher male mortality makes them scarce and the low value of children within marriage make women not as valuable to men.

\footnotetext{
${ }^{19}$ Remember that for simplicity the model assumes that there is no utility of remaining single.
} 


\begin{tabular}{|c|c|c|c|c|}
\hline & \multicolumn{2}{|c|}{$\begin{array}{l}\text { Model } \\
\text { (1) }\end{array}$} & \multicolumn{2}{|c|}{$\begin{array}{c}\text { France } 1999 \\
(2)\end{array}$} \\
\hline & Men & Women & Men & Women \\
\hline$\beta$ & \multicolumn{2}{|c|}{0.925} & & \\
\hline$k$ & \multicolumn{2}{|c|}{1.25} & & \\
\hline Age of First Marriage & 29.4 & 27.9 & 30.2 & 28.1 \\
\hline Sex Ratio of Singles & \multicolumn{2}{|c|}{1.13} & \multicolumn{2}{|r|}{1.16} \\
\hline Ever Married (\%) & 0.69 & 0.74 & 0.61 & 0.67 \\
\hline Fraction of Widows & & 0.07 & 0.02 & 0.10 \\
\hline Sex Ratio for Ever Married & \multicolumn{2}{|c|}{0.90} & \multicolumn{2}{|r|}{0.87} \\
\hline Total Sex Ratio & \multicolumn{2}{|c|}{0.96} & \multicolumn{2}{|r|}{0.97} \\
\hline
\end{tabular}

Table 3: Comparison Between Model and France Census 1999

\subsection{France}

Table 3 and Figure 16 compare the model results with the 1999 France census. Data is from the National Institute for Statistics and Economic Studies - France for the entire population who lives in metropolitan areas. The model results are for $\beta=0.925$ and $k=1.25$. Notice than in this case the predictions of the model match quite accurately the data.

\subsection{Sweden}

Here we compare the model results with data for the year 2000 in Sweden. Data is form Statistics Sweden for the entire population. The model results are for $\beta=0.95$ and $k=1.25$. Here the model predicts accurately the age at first marriage for men (32.3 years) and women marry in average one year earlier in the data than when the model results predict (30.1 versus 31.3 years). Thus, the model predict a smaller age difference than the actual mean age difference (1 year versus 2.3 years).

\subsection{US in Previous Decades}

Figure 18 shows the median age at first marriage in US since 1940. The tendency to delaying marriage over the last decades is clear. This reflects an increase in both mean and variance of the age at marriage for men and women. For example 


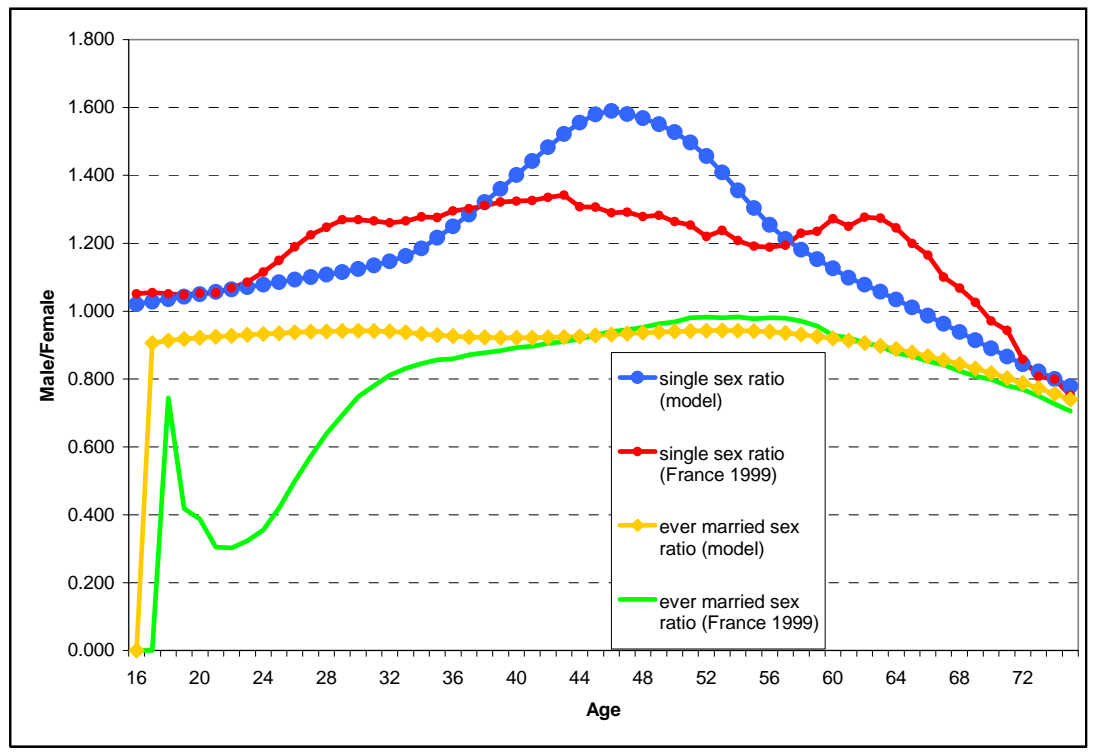

Figure 16: Sex Ratio for Single and Ever Married. Census 1999 (France) and Model $(k=1.25, \beta=0.925)$ with mortality rates in France.

the mean age at first marriage for white males married between 1960 and 1965 was 23.5 years, and 21 years for white females. In 1975-80 the mean for white males was 23.9 and 21.8 for white females. Note that the age difference between men and women appear to be quite stable. ${ }^{20}$

Figure 19 shows the sex ratio (single males/single females) for whites in the US for 1960, 1980 and 2000. The age pattern of sex ratios appear to have changed over time. First, the pattern of the sex ratio by age is flatter in 1980 with respect to 1960 and even more flat in 2000. Second, the "peak" sex ratio in 1960 and 1980 was in the mid 20's. This peak moved to the mid 30's in 2000 census. Figure 20 shows the pattern of the sex ratio (single males/single females) for blacks in the US for 1960, 1980 and 2000. As in the case of whites, the pattern appear to have changed over time. While in 1960 the graphic shows a very similar pattern to the one for whites, that is not the case for 1980 and 2000 .

In the case of 1960 , in order to achieve a similar pattern to that of the data it would be necessary to assume that women's fecundity starts to decrease at age

\footnotetext{
${ }^{20}$ For an empirical study about the change in marriage patterns in the US in last decades, see Rose (2001).
} 


\begin{tabular}{|c|c|c|c|c|}
\hline & \multicolumn{2}{|c|}{$\begin{array}{l}\text { Model } \\
(3)\end{array}$} & \multicolumn{2}{|c|}{$\begin{array}{c}\text { Sweden } 2000 \\
(4)\end{array}$} \\
\hline & Men & Women & Men & Women \\
\hline$\beta$ & \multicolumn{2}{|c|}{0.95} & & \\
\hline$k$ & \multicolumn{2}{|c|}{1.25} & & \\
\hline Age of First Marriage & 32.3 & 31.3 & 32.4 & 30.1 \\
\hline Sex Ratio of Singles & \multicolumn{2}{|c|}{1.12} & \multicolumn{2}{|c|}{1.24} \\
\hline Ever Married (\%) & 0.64 & 0.68 & 0.55 & 0.64 \\
\hline Fraction of Widows/ers & & 0.05 & 0.03 & 0.08 \\
\hline Sex Ratio for Ever Married & \multicolumn{2}{|c|}{0.95} & \multicolumn{2}{|c|}{0.87} \\
\hline Total Sex Ratio & \multicolumn{2}{|c|}{1.00} & \multicolumn{2}{|c|}{1.01} \\
\hline
\end{tabular}

Table 4: Comparison Between Model and Census 2000 (Sweden)

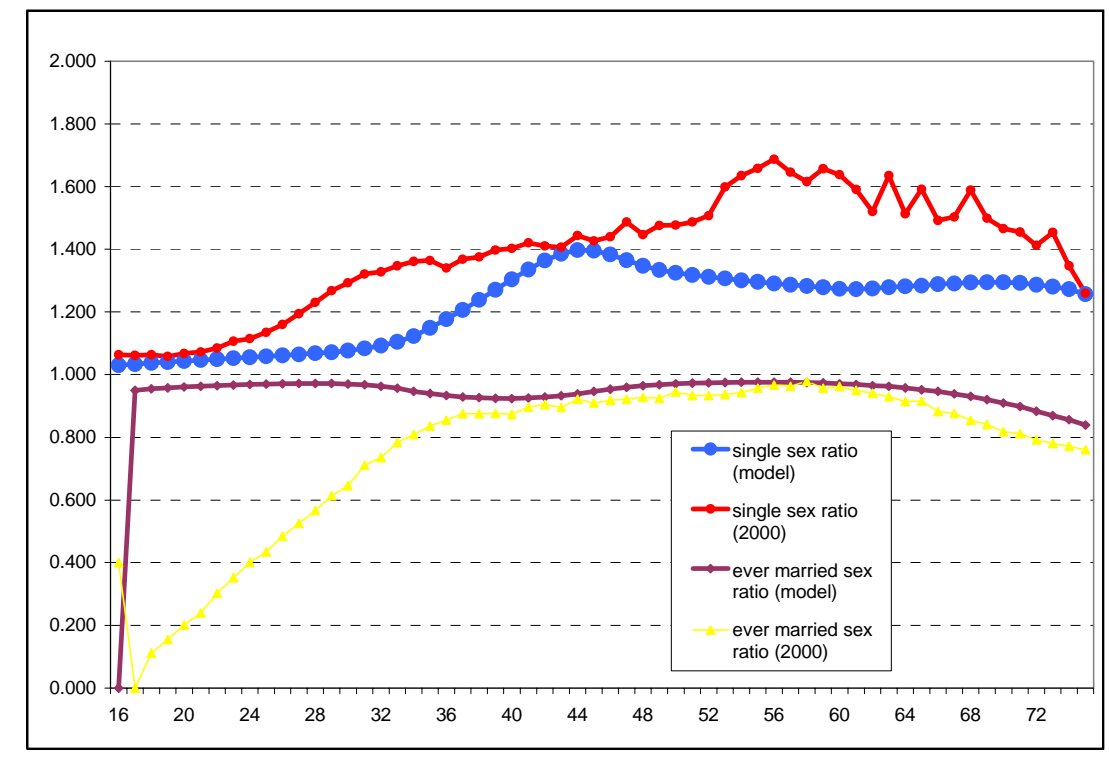

Figure 17: Sex Ratio for Single and Ever Married. Census 2000 (Sweden) and Model $(k=1.25, \beta=0.95)$ with mortality rates in Sweden. 
24. This is a signal that this 2 parameter model is not enough in order to explain the behavior of the marriage market 40 years ago.

The last few decades observed more similar roles for men and women. For example, in the US, the level of education have become increasingly similar and women's labor participation have increased dramatically in the last 20 years. Moreover, marriage specialization have consequently decreased ${ }^{21}$, and traditional roles in marriage are not so common as they were in the past. Even though social norms have changed making that roles of men and women became more and more similar, the fecundity horizon differences will persist and that can be an explanation of why women still tend to marry older men.

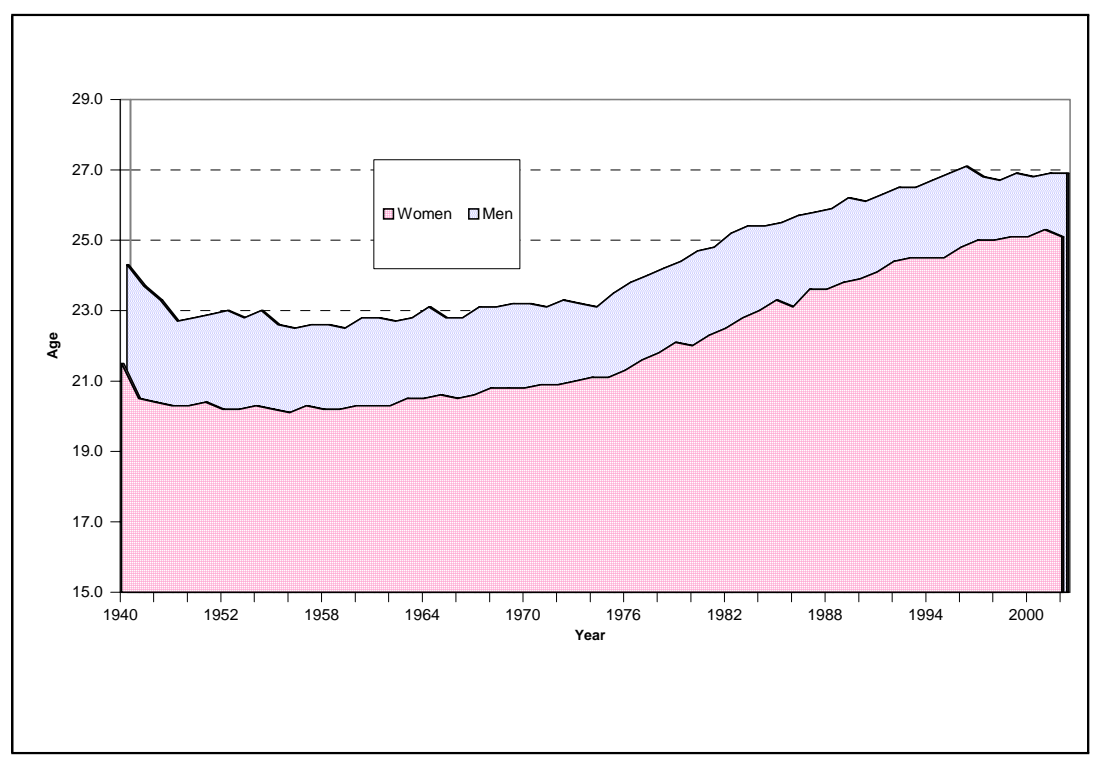

Figure 18: Median Age at First Marriage in the US

\subsection{Developing Countries}

Figure 21 shows the sex ratio by age for Kenya and Vietnam in 1999 and Mexico in 2000. It easy to tell that the data for developed countries match better with the model that the one for developing countries. Notice than, for these countries the pattern is very different than the in the case of the US or the European

\footnotetext{
${ }^{21}$ For a study on the decline in marriage specialization, see Lundberg and Rose (1998)
} 


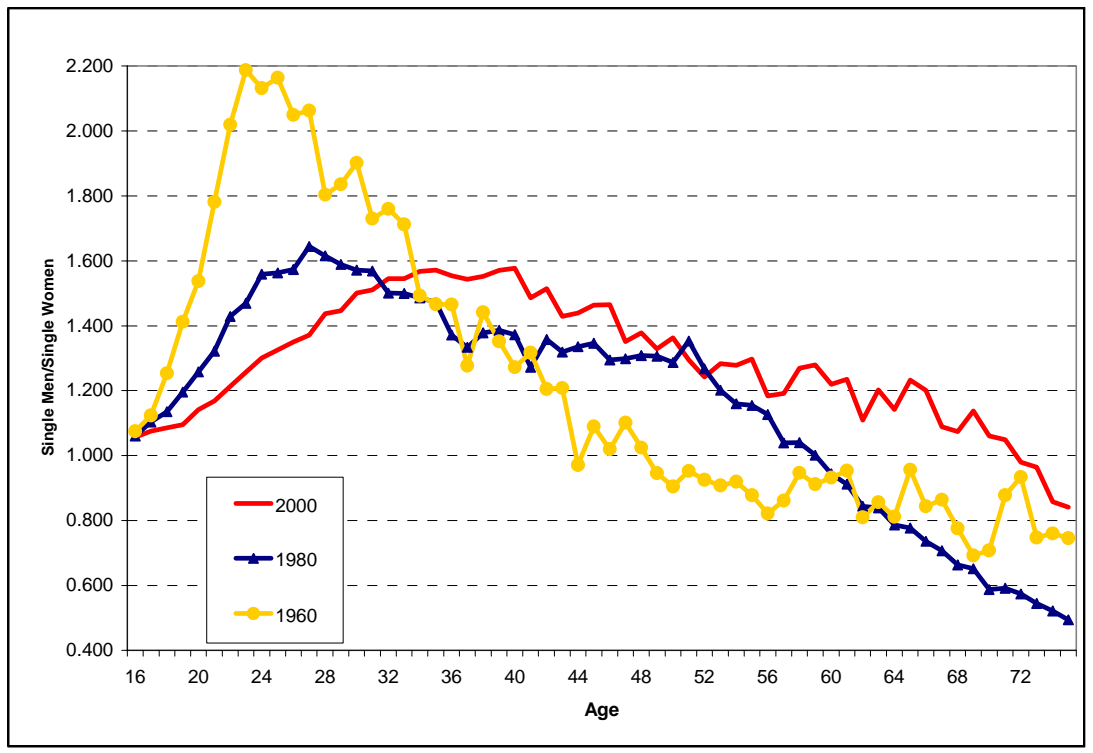

Figure 19: Sex Ratio (Single Men/Single Women) in the US (Whites)

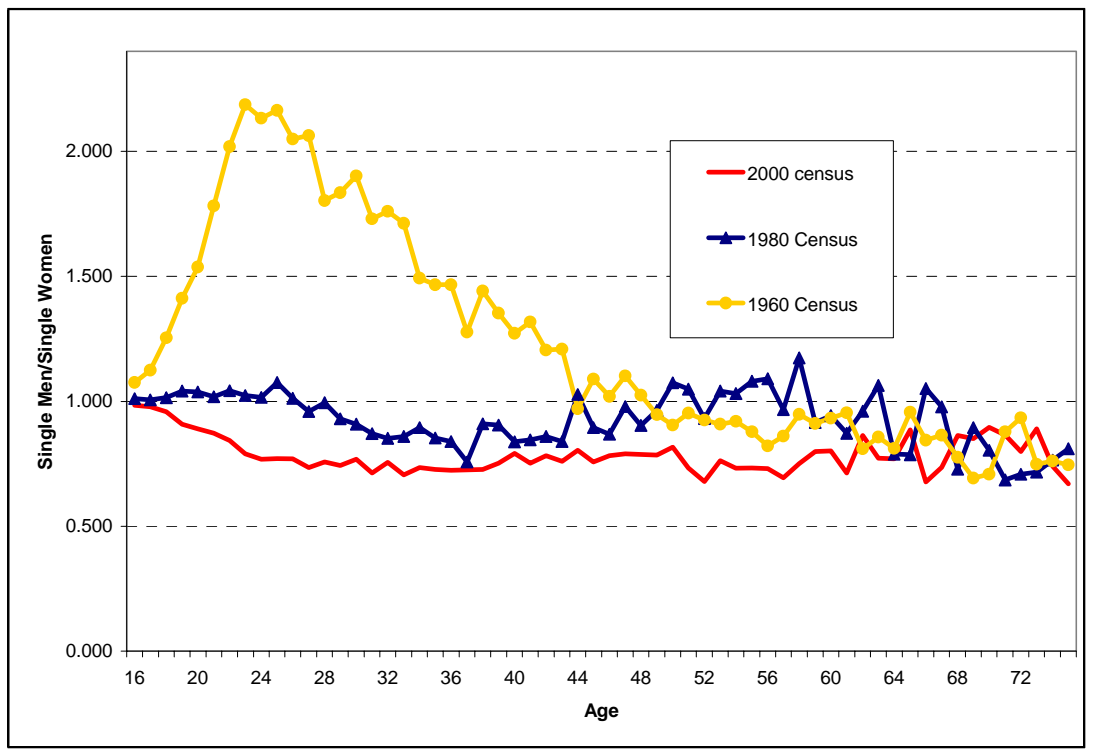

Figure 20: Sex Ratio (Single Men/Single Women) in the US (Blacks) 
countries described above. In the three countries of the figure the sex ratio reaches a maximum at ages 24-27 and then decreases sharply. This is somewhat similar to the pattern in the US in 1960 (Figure 19 above).

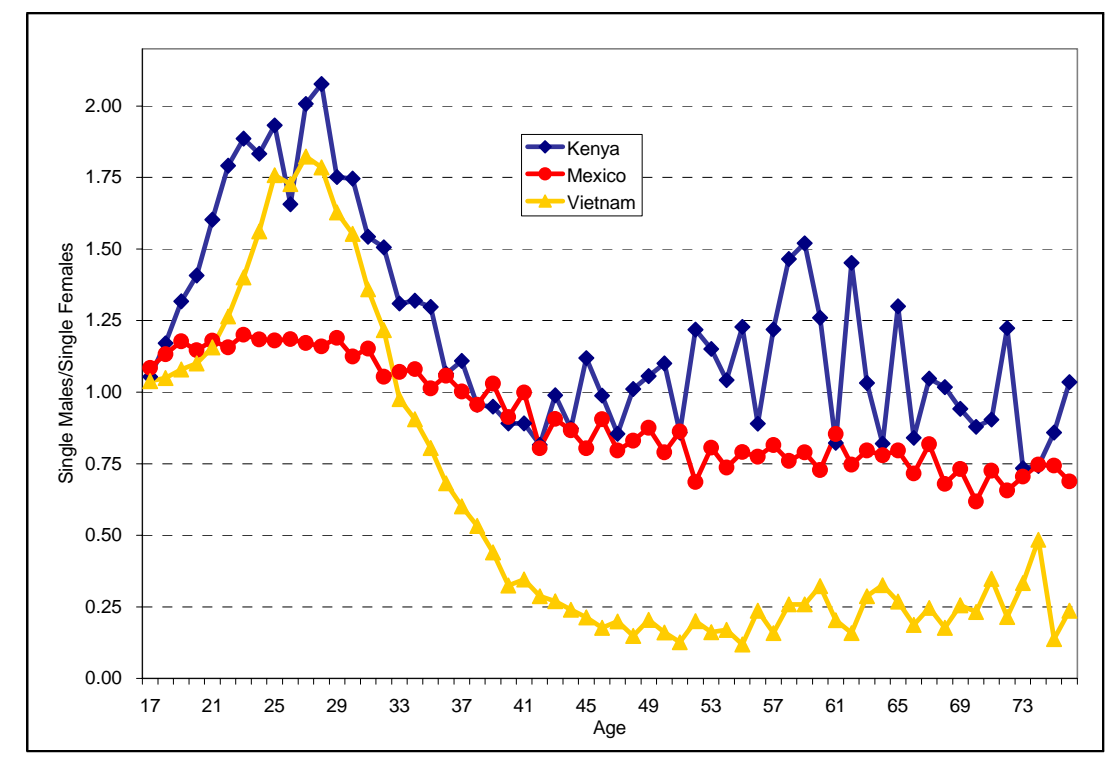

Figure 21: Ratio Single Men/Single Women. Kenya and Vietnam, 1999 and Mexico 2000

In summary, this model does a better job explaining the patterns in developed countries than in developing countries, and in recent times compared to previous decades. In this model the evolution of the sex ratio with age is entirely determined by the different fecundity horizon of men and women. For that reason, all other differences between sexes intentionally excluded in this model, obviously also play a role in marriage behavior. Social norms may also be important. For example, when we find a peak in the sex ratio around 25 years old, as in Figure 21, or the sharply increase in the sex ratio in the early twenties in US in 1960, perhaps we are talking about some "social limit" to the age when women should marry. What is important is that his social norm appear to be more significant in societies where traditional marital roles are still well defined. 


\section{Conclusion}

This paper shows that asymmetric fecundity horizons between men and women alone are sufficient to generate a stylized fact that holds across many societies - on average younger women marry older men. The 2-parameter model developed to address this fact also accounts for other stylized facts about the marriage market. The contribution of this paper is to provide a framework where age of marriage is determined by biological concerns, ignoring potential gains of specialization. In the last few decades, men and women have become more alike in their social roles. Female labor force participation has increased dramatically in many societies and differences in education level are disappearing in more developed countries. The model fits the data well for recent decades in the United States, France and Sweden. A second contribution of this work is to show how the effect of asymmetries in mortality between men and women can affect the structure of the marriage markets. This plays a particularly important role for Black Americans.

Countries with advanced post-industrial demographics (e.g. France, Sweden and the U.S.) have ages at first marriage and an age pattern of sex ratios that closely resemble the model's predictions. In developing countries, however, where traditional gender roles are still important the model predictions fail to explain the patterns in the data. This failure suggests that in these contexts the model is incomplete. Now that we have a better understanding of the role of biology, one natural extension of this paper is to incorporate features of the labor market that do vary across countries and over time. Of particular importance are both the earnings ability of men in a society and the relative earnings ability of men versus women. This model is designed to incorporate these extensions. 


\section{Appendix}

\section{Complete Proof of Theorem 1}

By Equations (11) and (12), we know that

$$
\begin{aligned}
R^{m} & =\frac{R_{\text {old }}^{m}}{k(1+\beta)} \\
R^{f} & =\frac{R_{\text {old }}^{f}}{k(1+\beta)}
\end{aligned}
$$

Then, it will be sufficient to show existence and uniqueness for $R_{\text {old }}^{m}$ and $R_{\text {old }}^{f}$ to show them for $R^{m}$ and $R^{f}$.

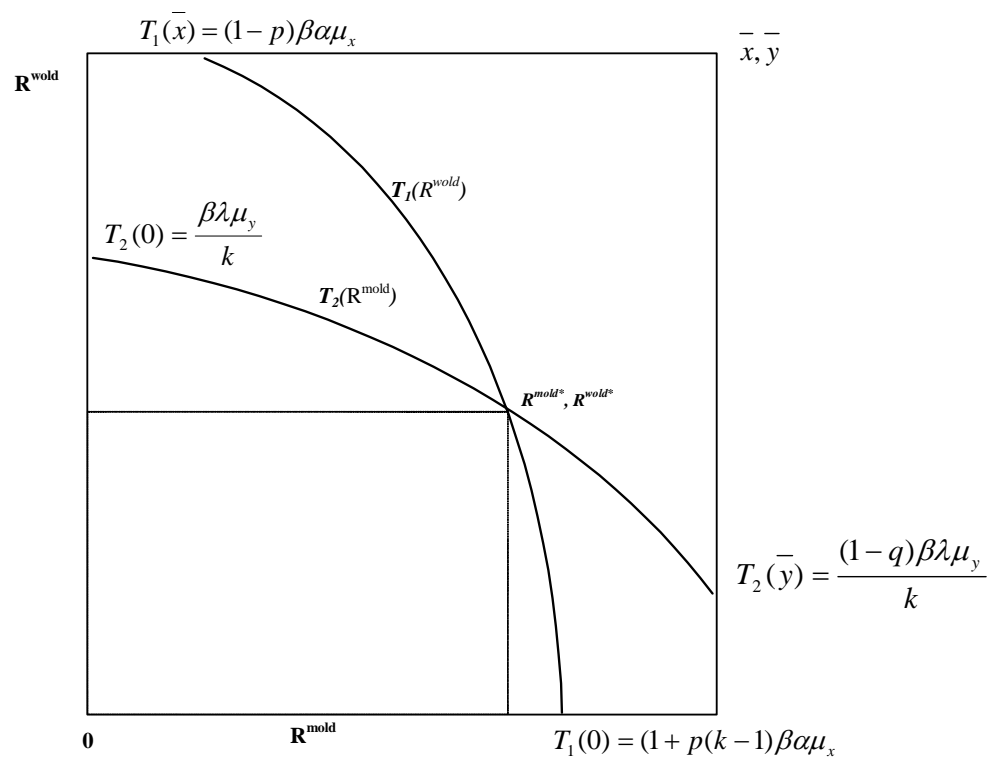

Figure 22: 
Lets start defining the reaction functions

$$
\begin{aligned}
& R_{\text {old }}^{m}=T_{1}\left(R_{\text {old }}^{f}\right)=\eta^{m} \beta\left[(1-p)+k p\left(1-G_{m}\left(R_{\text {old }}^{f}\right)\right)\right] \bar{x} \\
& R_{\text {old }}^{f}=T_{2}\left(R_{\text {old }}^{m}\right)=\frac{\beta \eta^{f}\left(1-q G_{f}\left(R_{\text {old }}^{m}\right)\right) \bar{y}}{k}
\end{aligned}
$$

By definition, $p \in[0.5,1]$ and $q \in[0.5,1]$. Differentiating (38) and (38) we see that $T_{1}$ and $T_{2}$ are strictly decreasing in $R_{\text {old }}^{f}$ and $R_{\text {old }}^{m}$ respectively.

$$
\begin{aligned}
& T_{1}^{\prime}\left(R_{\text {old }}^{f}\right)=-k p \eta^{m} \beta g_{m}\left(R_{\text {old }}^{f}\right) \bar{x}<0 \\
& T_{2}^{\prime}\left(R_{\text {old }}^{m}\right)=-\frac{q \beta \eta^{f} g_{f}\left(R_{\text {old }}^{m}\right) \bar{y}}{k}<0
\end{aligned}
$$

Now, using the condition in (5), it is easy to show that the intercepts are

$$
\begin{aligned}
T_{1}(0) & =(1+p(k-1)) \eta^{m} \beta \bar{x}<x \max \\
T_{2}(0) & =\frac{\beta \eta^{f} \bar{y}}{k}<y \max \\
T_{1}(\text { ymax }) & =(1-p) \eta^{m} \beta \bar{x} \geq 0 \\
T_{2}(x \max ) & =\frac{\beta \eta^{f}(1-q) \bar{y}}{k} \geq 0
\end{aligned}
$$

The above conditions, summarized in the figure, rule out any corner solution and at the same time guarantee the existence of at least one interior solution. The next step will be to show that there is a unique equilibrium in the model. We know that

$$
\begin{aligned}
R_{\text {old }}^{m} & =T_{1}\left(R_{\text {old }}^{f}\right)=T_{1}\left(T_{2}\left(R_{\text {old }}^{m}\right)\right) \\
& \equiv H\left(R_{\text {old }}^{m}\right)
\end{aligned}
$$

where

$$
H\left(R_{\text {old }}^{m}\right)=\eta^{m} \beta\left[(1-p)+k p\left(1-G_{m}\left(T_{2}\left(R_{\text {old }}^{m}\right)\right)\right)\right] \bar{x}
$$

To ensure uniqueness, we need a fixed point of $H($.$) . Thus, we need to show$ that $H\left(R_{\text {old }}^{m}\right)$ is a contraction mapping. that is

$$
\begin{aligned}
\left\|H\left(R_{\text {old }}^{m}\right)-H\left(R_{\text {old }}^{m}\right)\right\| & \leq \partial\left\|R_{\text {old }}^{m}-R_{\text {old }}^{m}\right\| \\
\text { where } 0 & <\delta<1
\end{aligned}
$$


To show that $H$ is a contraction mapping, it is enough to prove that

$$
H^{\prime}\left(R_{\text {old }}^{m}\right) \leq \delta<1 \quad \forall R_{\text {old }}^{m} \in[0, x \max ]
$$

But

$$
H^{\prime}\left(R_{\text {old }}^{m}\right)=T_{1}^{\prime}\left(T_{2}\left(R_{\text {old }}^{m}\right)\right) \cdot T_{2}^{\prime}\left(R_{\text {old }}^{m}\right)
$$

Using (2), (3) (4), (38), (39)and the assumption that $m_{1}=f_{1}$, substituting in (40) and manipulating, we get

$$
H^{\prime}\left(R_{\text {old }}^{m}\right)=\left(\mu\left(\frac{M}{f}\right)^{\theta}\right)^{2} \beta^{2}\left(\frac{m_{1}}{M}\right)^{2} g_{f}\left(R_{\text {old }}^{m}\right) g_{m}\left(T_{2}\left(R_{\text {old }}^{m}\right)\right) \overline{y x}
$$

By assumption, we know that $\left(\mu\left(\frac{M}{f}\right)^{\theta}\right) \leq 1$, that $\frac{m_{1}}{M} \leq 1$ and that $\beta<1$. Hence, it will be sufficient for $H^{\prime}\left(R_{\text {old }}^{m}\right)$ to be a contraction mapping if we have

$$
g_{f}\left(R_{\text {old }}^{m}\right) g_{m}\left(T_{2}\left(R_{\text {old }}^{m}\right)\right) \leq C
$$

where

$$
C<\frac{1}{\overline{y x}}
$$

Therefore, we have that

$$
H^{\prime}\left(R_{\text {old }}^{m}\right)<1
$$

\section{Proof of Proposition 3}

By the assumption above, $G_{f}()=.G_{m}($.$) . First, by (11) and (12), and using$ $(2),(3)$ and (4), we define the difference between reservation values of men and women, $R^{m}$ and $R^{f}$, as follows

$$
R^{m}-R^{f}=\frac{\beta \bar{x}\left(\frac{M}{f}\right)^{\theta}\left(m_{1}\left(1-G_{f}\left(R_{\text {old }}^{m}\right)\right)+k f_{1}\left(1-G_{f}\left(R_{\text {old }}^{f}\right)\right)+m_{2}-f_{2}\right)}{k(1+\beta) M}
$$

taking derivatives with respect to $k$

$$
\frac{\partial}{\partial k}\left(R^{m}-R^{f}\right)=\frac{\beta \bar{x}\left(\frac{M}{f}\right)^{\theta}\left(m_{1}\left(1-G_{f}\left(R_{\text {old }}^{m}\right)\right)+m_{2}-f_{2}\right)}{k^{2}(1+\beta) M}
$$


For $k=1$, we know that men and women face exactly the same problem. Then $R^{m}=R^{f}, h_{1}=w_{1}$ and $m_{2}=f_{2}$. By the proof of Theorem 1 also $R_{\text {old }}^{m}<1$. So,

$$
\frac{\partial}{\partial k}\left(R^{m}-R^{f}\right)_{k=1}=\frac{\beta \bar{x} m_{1}\left(1-G_{f}\left(R_{\text {old }}^{m}\right)\right)}{(1+\beta) M}>0
$$

Hence, $R^{m}>R^{f}$ if $k>1$, which completes the proof 


\section{References}

[1] Aiyagari, S., Greenwood J. and Nezih Guner, "On the State of the Union," Journal of Political Economy, 2000, vol. 108, no. 2.

[2] Becker, Gary S., 1973, "A Theory of Marriage: Part I," Journal of Political Economy, 1973, vol. 81, 813-846.

[3] Bergstrom, Theodore and Mark Bagnoli, "Courtship as a Waiting Game". Journal of Political Economy, 1993, vol. 101, no. 1.

[4] Berkeley Mortality Database. http://demog.berkeley.edu/wilmoth/mortality

[5] Bergstrom, Theodore and Robert Schoeni "Income Prospects and Age at Marriage", Journal of Population Economics (1996) 9: 115-130

[6] Brien, Michael, "Racial Differences in Marriage and the Role of Marriage Markets". Journal of Human Resources, 1997, XXXII.4.

[7] Brien, M. Lillard, L., and Steven Stern "Cohabitation, Marriage, and Divorce in a Model of Match Quality". Mimeo. University of Virginia, September 2002.

[8] Burdett, Kenneth and Melvyn Coles, "Marriage and Class". Quarterly Journal of Economics, February 1997.

[9] Burdett , Kenneth and Melvyn Coles, "Long Term Partnership Formation: Marriage and Employment". The Economic Journal. June 1999.

[10] Cornelius, Tracy J. "A Search Model of Marriage and Divorce", Review of Economic Dynamics 6 (2003), 135-155.

[11] Fitzgeralg, John, "Welfare Durations and the Marriage Market: Evidence from the Survey of Income and Participation", Journal of Human Resources, 1991, XXVI, 3.

[12] Gale, David and Lloyd Shapley, "College Admision and the Stability of Marriage", American Mathematical Monthly, 69 (1962).

[13] Greenwood, J., Guner, N. and J. Knowles (2002) "More on Marriage, fecundity and Distribution of Income", International Economic Review, forthcoming. 
[14] Guttentag, Marcia and Paul Secord "Too Many Women? The Sex Ratio Question". 1983. Sage Publications

[15] National Institute for Statistics and Economic Studies - France. census 1999. http://www.insee.fr

[16] Kolmogorov, A. N. and . S. V. Fomin, "Introductory Real Analysis". 1970. Dover Publications.

[17] Lichter, D. , LeClere, F. and D. McLaughlin, "Local Marriage Markets and the Marital Behavior for Black and White Women".American Journal of Sociology, 1991, 96, 4.

[18] Lichter, D. , McLaughlin, D., Kephart, G. and D. Landry, "Race and the Retreat from Marriage: A Shortage of Marriageable Men?". American Sociological Review, 1992, 57, 6

[19] Lundberg, Shelly and Elaina Rose "The Determinants of Specialization within Marriage". Mimeo. University of Washington. 1998

[20] Mortensen, Dale "Matching: Finding a Partner for Life or Otherwise". American Journal of Sociology 94 (Supplement), 1988.

[21] Pollak, R. and Eyal Winter "Random Matching in Marriage Markets". Mimeo. Washington University in St.Louis. 1997

[22] Pissarides, Christopher, "Equilibrium Unemployment Theory". 1990. Oxford: Basil Blackwell

[23] Pissarides, Christopher, "The Economics of Search" (2000). Encyclopedia of the Social and Behavioral Sciences, forthcoming

[24] Rose, Elaina, "Marriage and Assortative Mating: How Have the Patterns Changed?". Mimeo. University of Washington. December, 2001

[25] Roth, Alvin and Marilda Sotomayor "Two Sided Matching". 1990. Cambridge University Press.

[26] Ruggles, Steven, Matthew Sobek et al. Integrated Public Use Microdata Series: Version 3.0. Minneapolis: Historical census Projects, University of Minnesota, 2003. URL: http://www.ipums.org 
[27] Seitz, Shannon, "Accounting for Racial Differences in Marriage and Employment". Mimeo. Queen's University . September 2002.

[28] Tertilt, Michele, "The Economics of Brideprice and Dowry: A Marriage Market Analysis". University of Minnesota. Mimeo. June 2002.

[29] Siow, Aloysious, "Differential Fecundity, Markets, and Gender Roles". Journal of Political Economy, 1998, vol. 106, no. 2.

[30] Schmidt, Lucie, "Murphy Brown Revisited: Human Capital, Search and Nonmarital Childbearing among Educated Women". Mimeo. University of Michigan, March 2002.

[31] Smith, Lones, "The Marriage Market with Search Frictions". Mimeo. University of Michigan, September 2002.

[32] Statistics Sweden. http://www.scb.se

[33] U.S. census Bureau, Annual Demographic Supplement to the March 2002 Current Population Survey, Current Population Reports, Series P20-547, "Children's Living Arrangements and Characteristics: March 2002" and earlier reports.

[34] Weiss, Y. and Robert Willis, "Transfers among Divorced Couples: Evidence and Interpretation", Journal of Labor Economics, 1993, vol 11, no 4.

[35] Wilson, W. and Kathryn Neckerman. 1986, "Poverty and Family Structure: The Widening Gap between Evidence and Public Policy Issues", in Fighting Poverty: What Works and What Doesn't, ed. Sheldon H. Danzinger and Daniel H. Weinberg, 232-59. Cambridge: Harvard University Press

[36] Winkler, Anne "Earnings of Husbands and Wives in Dual-Earner Families". Monthly Labor Review. April 1998

[37] Wood, Robert G., "Marriage Rates and Marriageable Men: A Test of the Wilson Hypothesis" Journal of Human Resources, 1995, XXX, 1. 